Stability and Change in the Big Five and Big Six: New Tests of the Maturity and Cumulative Continuity Principles

\author{
Cory K. Costello, Sanjay Srivastava, and Gerard Saucier \\ University of Oregon
}

WORKING PAPER - SUBJECT TO REVISION

$06 / 23 / 2017$

Author Note

Cory K. Costello, Sanjay Srivastava, and Gerard Saucier, University of Oregon.

This material is based upon work supported by the National Science Foundation under Grant \# 0921842.

Correspondence should be sent to: Cory K. Costello, Department of Psychology, 1227 University of Oregon, Eugene, OR 97403, email: ccostell@uoregon.edu. 


\begin{abstract}
The maturity principle and cumulative continuity principle have been fundamental in understanding adult development of personality traits. We tested new predictions derived from both principles for Honesty-Propriety, a factor from the newer Big Six model, as well as for the original Big Five domains. We also tested hypotheses about lower-order Big Five aspects, gender differences in change, and a plateau in rank-order stability in early and middle adulthood. Data came from a national sample of U.S. adults $(N=858)$ who were assessed via both self- and informant reports in an accelerated longitudinal design with four annual waves. Consistent with the maturity principle, self-reports of Honesty-Propriety increased with age; changes in informant reports were directionally similar but nonsignificant. We also replicated previous findings supporting the maturity principle: Agreeableness, Conscientiousness, and Emotional Stability all increased with age. Analyses of lower-order aspects showed largely similar patterns of change at a different level of the personality taxonomy. Women increased in Emotional Stability more than men did. In tests of the cumulative continuity principle, we did not find evidence of increasing rank-order stability from age 18 to 58. This suggests a modification to the cumulative continuity principle in which rank-order stability is relatively unchanging across this period of life, what we term the working years plateau.
\end{abstract}




\section{Stability and Change in the Big Five and Big Six: New Tests of the Maturity and Cumulative Continuity Principles}

How does personality change over the course of adulthood, and what explains change and stability? Researchers have recently been converging on a consensus description of stability and change in the Big Five traits, and in recent years have been actively testing accounts of the underlying mechanisms. With regard to mean-level change, the consensus is that there are meaningful normative changes in some personality characteristics: people tend to increase in Conscientiousness and Agreeableness, and decrease in Neuroticism with age. This empirical pattern has been explained by the maturity principle, which explains these changes in terms of functional and socio-analytic understandings of maturity (Caspi et al., 2004; Hogan \& Roberts, 2004; Roberts et al., 2008). With regard to rank-order stability, the consensus is that personality traits are moderately stable in early adulthood, and they become even more stable with increasing age. This empirical observation of increasing stability has been explained via the cumulative continuity principle, which explains increasing stability via the accumulation of stabilizing mechanisms (e.g., gene-environment correlations, identity processes, etc.) across the lifespan (Caspi, Roberts, \& Shiner, 2004; Roberts, Wood, \& Caspi, 2008).

Both principles have been supported by evidence about mechanisms, such as the importance of social roles in both processes (Roberts et al., 2008), which has helped bolster these theories. However, because the observations of mean-level change and rank-order stability predated the theorized principles, neither has been directly tested with theoretically novel predictions about mean-level change or rank-order stability in personality traits.

Such a test may now be possible. In recent years, evidence has emerged for a Big Six personality structure, which adds Honesty-Propriety to the familiar Big Five (Saucier, 2009; 
Saucier \& Srivastava, 2015). On its own, a descriptive investigation of change and stability in Honesty-Propriety would be of substantial interest. In addition, however, because we can derive predictions about Honesty-Propriety from the maturity and cumulative continuity principles, the addition of this sixth domain provides a unique opportunity to evaluate new predictions based on both principles.

In the present study, we tested new hypotheses about maturity and cumulative continuity in Honesty-Propriety. We also examined the original Big Five, with a goal of not only replicating previous findings but also investigating new questions about adult personality development. Increases in rank-order stability are often described as continuous, but some evidence suggests that stability may stay at a plateau in early and middle adulthood. Previous evidence has been mixed as to whether changes at a more granular level of analysis, such as in Big Five aspects, simply mirror the broader factors or show distinct patterns. Gender differences in change have been observed in some studies (particularly for Neuroticism) but not in others. And in a research domain that relies heavily on self-report methods, convergence or divergence with informant reports could shed light on how to interpret changes.

We investigated all of these questions in a large and diverse sample of United States adults using an accelerated longitudinal design with four annual assessment waves with close attention to controlling bias and noise in measurement, including conducting preliminary tests of measurement invariance and estimating stability and change with latent-variable models whenever possible.

\section{Honesty-Propriety and Hierarchical Representations of Personality}

An investigation of personality change must adopt a structural model of personality to delineate which constructs to base theory and measurement on (Saucier \& Srivastava, 2015). 
Although the Big Five has been the dominant structural model in personality science for some time (John, Naumann, \& Soto, 2008), there is accumulating evidence that a Big Six framework is more generalizable across languages and captures more information than the Big Five (Saucier \& Srivastava, 2015). Much like the Big Five, the Big Six was found through analyzing the factor structure of ratings made on large sets of personality descriptors. It first emerged when conducting lexical analyses on previously unexamined languages (e.g., Korean, French; Ashton et al., 2004) and more inclusive sets of adjectives in a diverse range of previously studied languages (Saucier, 2009). Interestingly, four of the domains closely resemble their Big Five counterparts; one domain, Agreeableness, changes to center on even-temperedness and patience in the Big Six (instead of its core of compassion/warmth in Big Five models) ${ }^{1}$. The Big Six also adds a sixth domain which has been called Honesty-Propriety by some (Saucier, 2009; Saucier \& Srivastava, 2015) or Honesty-Humility by others (Ashton \& Lee, 2007; Ashton et al., 2004) in broadly converging lines of research. Measures of the Big Six have demonstrated greater predictive validity than comparable measures of the Big Five, suggesting that Honesty-Propriety captures something unique and consequential not otherwise captured by the remaining five domains (Thalmayer, Saucier, \& Eigenhuis, 2011).

What is Honesty-Propriety? In a broad sense, it represents the tendency to follow rules and norms that help people get along, and as well as restraining oneself from getting ahead when doing so conflicts with social rules and norms (Saucier, 2009). The converging HonestyHumility factor has been similarly described as concerning how honest and fair one is with others (Ashton \& Lee, 2007). Examples of items used to measure Honesty-Propriety include "Uses others for his or her own ends" (reversed) and "sticks to the rules" (Thalmayer et al., 
2011). Thus, honesty, fairness, and moral conduct more broadly seem to be at the core of either interpretation of the sixth domain.

Another way to understand Honesty-Propriety comes from its place within hierarchical representations of personality. Going back to Digman's (1997) work, researchers have recognized that there are two higher-order factors above the Big Five, as well as aspects and facets below the Big Five (i.e., lower-order factors; DeYoung, Quilty, \& Peterson, 2007). Digman gave these higher-order factors the provisional labels alpha and beta; other researchers have used other labels, such as Stability and Plasticity (DeYoung, 2006), and the labels that we have preferred in our work, Social Self-Regulation and Dynamism (Saucier \& Srivastava, 2015). Honesty-Propriety unambiguously joins Agreeableness and Conscientiousness as part of Social Self-Regulation when included in these higher-order models. Dynamism includes Extraversion and Openness, while Neuroticism is split between the higher-order factors.

In interpretations of the higher-order Social Self-Regulation factor, a common theme has been the internalization of social and moral norms. Indeed, Digman (1997) considered socialization as a possible label for his analogous alpha factor. Moreover, Social Self-Regulation can be thought of as relevant to Hogan's (1983) concept of “getting along” or Bakan's (1966) analogous concept of communion, which is thought to concern the pressures of social bonding and cooperation inherent in social life. Although these features were initially identified in research on the structure of individual differences, they closely resemble the proposed basis of the maturity principle in lifespan development, which we discuss next.

\section{The Maturity Principle and Mean-Level Changes in Personality}

The maturity principle defines maturity as possessing the characteristics and abilities to be a functioning, productive, and engaged member of society (Caspi et al., 2004; Roberts et al., 
2008). As such, it predicts that populations as a whole tend to increase in the characteristics necessary for this developmental goal; within the Big Five framework, this has been largely understood as increases in Conscientiousness, Agreeableness, and Emotional Stability, as these characteristics facilitate the productivity, compassion, and steadiness necessary for optimal functioning in adult society. The maturity principle grew out of an older conceptualization of psychosocial maturation, socialization, which describes the process by which individuals internalize the prescriptive social and moral norms of their society, ultimately increasing their ability to function in that society (Helson \& Wink, 1987). Notably, the maturity principle posits that the three Big Five characteristics that share the higher-order trait Social Self-Regulation are the ones that increase with age. Empirical evidence supports the idea that this form of maturity is normative. Aging is associated with increases in Conscientiousness and Agreeableness, and decreases in Neuroticism in longitudinal studies (e.g., Specht et al., 2011), cross-sectional studies (Soto et al., 2011; Srivastava et al., 2003), and meta-analyses (Roberts et al., 2006).

It is worth noting that other conceptions of maturity have instead emphasized individuation and self-actualization, which should manifest in increases in Dynamism, particularly in Openness to Experience (Helson \& Wink, 1987). However there is very little evidence of this form of maturity: Openness to experience shows small declines with age in some studies (Srivastava et al., 2003; Specht et al., 2011), while other studies have instead found virtually no change in Openness to Experience (Roberts et al., 2006; Soto et al., 2011).

In the present study we submitted the maturity principle to closer scrutiny by testing a novel hypothesis that we would observe mean-level increases in Honesty-Propriety. HonestyPropriety is part of the higher-order Social Self-Regulation domain, and largely concerns following social and moral norms (Saucier \& Srivastava, 2015; Saucier et al., 2014). Thus, 
insofar as the maturity principle reflects socialization, we should expect to find mean-level increases in Honesty-Propriety, just as we do with the other dimensions within Social SelfRegulation.

\section{Mean-Level Change Beyond the Maturity Principle}

The maturity principle has been central to understanding mean-level changes in personality across the lifespan. However, changes at the relatively narrower level of facets and gender differences in mean-level change are not captured by the maturity principle but are nonetheless important in characterizing adult development of personality traits.

Change at the level of facets and aspects. A few studies have looked at mean-level change in aspects or facets. Some of these studies have identified diverging patterns where facets change in different directions within the same larger domain, whereas other studies have largely found consistency. Because there is not yet a consensus on the lower-level structure of the Big Five, the available studies have often used different taxonomies (see Soto et al., 2011 for a further discussion). For our investigation, we adopted one widely used model that divides each of the Big Five into two aspects: Agreeableness is divided into Compassion and Politeness, Conscientiousness is divided into Orderliness and Industriousness, Neuroticism is divided into Withdrawal and Volatility, Extraversion is divided into Assertiveness and Enthusiasm, and Openness/Intellect is divided into Openness and Intellect (DeYoung et al., 2007).

There is currently no research investigating normative change in the full ten-aspect model of the Big Five. However, studies based on different taxonomies of lower-level facets and traits allow an indirect basis for forming hypotheses. The facets of Extraversion have received relatively more attention in the literature than other facets, due to a classic finding that these facets show different age effects. Social Dominance has been found to increase with age whereas 
Social Vitality has been found to decrease with age (Roberts et al., 2006; see also Helson et al., 2002). However, one cross-sectional study on personality and age did not find normative increases in either Extraversion facet (Soto et al., 2011) and a second found small normative increases in both (Bleidorn et al., 2013), raising questions about the robustness of the original finding.

Other facets and aspects have been investigated less extensively, though some suggestive patterns have emerged. Some findings indicate that Orderliness, a facet of Conscientiousness, does not show the normative increases found in the overall domain or related facets (e.g., Industriousness or self-discipline; Jackson et al., 2009; Soto et al., 2011). Facets of Openness may have different age trends, with available research finding very small linear increases for Openness to Ideas in adulthood, and a small (i.e., nearly flat) U-shaped trend for Openness to Aesthetics (Soto et al., 2011); these are somewhat analogous to Intellect and Openness in the present study. The aspects of Agreeableness used in the present study (Compassion and Politeness) are somewhat similar to the facets investigated by Soto and colleagues (altruism and compliance); Soto and colleagues found little to no difference in normative trends of these facets. The aspects of Neuroticism in the present study (Withdrawal and Volatility) are not directly comparable with the facets investigated by Soto and colleagues (Anxiety and Depression). Because Honesty-Propriety is relatively new and its lower-order structure has not been studied as extensively, we did not attempt to investigate aspects or facets of it in the present study ${ }^{2}$.

Gender differences. It is clear that women and men have very different social roles, identities, and experiences, raising the question of whether they show different patterns of normative trait development (Helson, Pals, \& Solomon, 1997). Gender differences in normative personality change have received mixed support. Some studies have found virtually no gender 
differences in personality change (Helson et al., 2002; Roberts et al., 2006; Specht et al., 2011), whereas others have found gender differences for several of the Big Five. Neuroticism has received the most support for gender differences in change, with several studies finding that in early adulthood women are higher in Neuroticism than men, but that women show greater decreases than men with age, narrowing or eliminating the gender gap by middle- to lateadulthood (Soto et al., 2011; Srivastava et al., 2003). Other studies have not found this difference (Roberts et al., 2006; Specht et al., 2011). Gender differences in the relation between age and Agreeableness have been found in some studies, with women increasing slightly faster than men (e.g., Srivastava et al., 2003), but they have not been found in other studies (e.g., Soto et al., 2011). Similarly, Srivastava and colleagues found very small gender differences in the relation between age and Extraversion, but Soto and colleagues found that these differences did not persist beyond adolescence.

\section{Rank-Order Stability and the Cumulative Continuity Principle}

Personality psychologists have reached a broad consensus that the rank ordering of individual differences in personality is moderately stable during adulthood. That conclusion is largely based on a meta-analysis by Roberts and DelVecchio (2000), and it has been again found in more recent studies (e.g., Specht et al., 2011). Roberts and DelVecchio (2000) analyzed testretest correlations from longitudinal studies with a retest interval of 1 year or greater, classifying a wide variety of measures into Big Five domains as well as several other temperament and trait categories. The rank-order stabilities were remarkably similar across different Big Five trait domains. Age was a substantial moderator, with rank-order stability correlations of observed variables averaging around .3 in childhood, .5 to .6 in early adulthood, and reaching a plateau around .7 in late-middle adulthood (ages 50 to 70 ). 
This pattern of increasing stability has been explained via the cumulative continuity principle (Roberts et al., 2008). Increasing stability across the lifespan can result from several different mechanisms, including person-environment transactions where people select themselves into environments that support their existing traits, and identity processes where people develop an identity that then guides their behavior (Buss, 1987; McAdams, 2001; Roberts et al., 2008). The cumulative continuity principle holds that these different mechanisms accumulate across the lifespan, ultimately leading to stability increasing linearly with age (Roberts \& DelVecchio, 2000; Roberts et al., 2008). Supporting this position, evidence from a recent behavioral genetics meta-analysis found that environmental contributions to phenotypic stability increase with age, though this did not result in appreciable increases in phenotypic stability after age 30 (Briley \& Tucker-Drob, 2014).

Is there a working years plateau? Cumulative continuity is often summarized as “stability increases with age." However, there are reasons to question whether stability increases continuously and linearly with age throughout the entirety of adulthood. A closer look at Roberts and DelVecchio's (2000) meta-analysis reveals that rank-order stability estimates were similar for people in their 20s, 30s, and 40s ( $r$ 's from .57 to .62). Major jumps in stability seem to mainly occur at two times in adulthood: in the transition from adolescence to early adulthood (early 20s) and in late-middle-adulthood (50s or later). While Roberts and DelVecchio (2000) themselves noted this step-like pattern, uncertainty around the point estimates in their data made it unclear whether this was a reliable pattern or just a fluke of noisy data. They ultimately suggested that further research is needed to determine whether stability increases at these stages of life specifically, or if it increases linearly across the lifespan. 
One investigation that speaks to this question was a study by Watson and Humrichouse (2006), which looked at rank-order stability in a sample of newly married couples $(N=460)$. In analyses of self- and partner-reported Big Five traits, they found that rank-order stability in that sample was higher than in a comparison sample of college students, but within the newlywed sample only Agreeableness showed a significant age-related increase in stability. In another investigation, Lucas and Donnellan (2011) examined rank-order stability in a large cohortsequential panel study of Germans $(N=14,110)$ who completed an abbreviated Big Five measure. Lucas and Donnellan's analyses show an increase in stability from the youngest cohort (age 17 at first assessment) to the early-20s cohorts, and a drop in stability starting in the 60s. However, it is less clear (and was not explicitly tested) whether stability changes or is flat in the middle of that age range. Terraciano, Costa, and McCrae (2006) analyzed changes in rank-order stability of the Big Five between groups ages 30-50, 50-65, and 65+ at first assessment. They found no changes in stability through age 65 (and only Extraversion changed in stability later, declining in their over-65 group). Finally, in a recent meta-analysis, Ferguson (2010) observed increases in rank-order stability over the period from adolescence into adulthood but then less change during adulthood, although he did not formally test for changes within adulthood. To summarize across these different investigations, the literature to date is somewhat ambiguous about whether rank-order stability truly increases from the 20 s into the 50 s, with suggestive and sometimes contradictory observations but few studies actually testing for changes within this period.

What could cause a plateau in personality stability during this period of life? The cumulative continuity principle holds that stability results from selection into new roles and consolidation of an identity. The major normative changes in role and identity that bracket this 
period are changes in work roles: entering the work force, and retiring or preparing for retirement. When people go through these role and identity changes, they may change in ways that make personality increase in stability over the transition; but during the period in between, stability may be at an equilibrium. In our study, covering the range from age 20 to 55, we were able to evaluate stability during this period in a more granular way than previous studies have.

We are thus left with two hypotheses about the nature of age-related changes in stability. The first, which we label the unmodified cumulative continuity hypothesis, states that personality continuously becomes more stable as a function of age through all periods of adulthood. The second is a modified and more specific version of cumulative continuity, what we term the working-years-plateau hypothesis, in which stability is relatively unchanging across the bulk of early to middle adulthood (the 20 s through the 50 s).

Another issue that could be affecting estimates of stability concerns the effect of scale reliability on test-retest correlations. That is, test-retest correlations underestimate true personality stability to the extent that the scales used are not perfectly reliable. Existing studies which have attempted to correct for attenuation due to measurement error have used sub-optimal solutions such as disattenuating based on reliability estimates, which can under- or over-estimate stability (Schmitt, 1996). Moreover, measurement error could affect estimates of age differences in stability if measurement is not invariant across different age ranges studied. This could happen if measures with potentially differing reliability are administered to different age groups, which is a possibility in Roberts and Delvecchio's (2000) meta-analysis. This could also happen if the same measure is used across age groups, but is more or less reliable for different age groups (i.e., a lack of measurement invariance; Gregorich, 2006). Only one of the reviewed studies used latent-variable models and tested for measurement invariance, and that study had an abbreviated 
Big Five measure with just 3 items per scale (Lucas \& Donnellan, 2011). In the present study, we administered full-length scales in the self-report assessments and used structural equation modeling to correct for attenuation due to measurement error to both get a more accurate estimate of true personality stability, and to rule out the possibility that age differences are resulting from differing measurement quality across ages.

Retest stability also depends on the size of the retest interval. Big Five traits are less stable over longer intervals, but stability is a nonlinear function of interval length that approaches a nonzero asymptote as the interval increases (Fraley \& Roberts, 2005). This pattern is consistent with a theoretical model in which personality is affected by a mixture of very stable influences, such as consistently expressed genetic factors or lasting effects of early experience, along with more dynamic influences like recent life events. By comparison, if personality was only a function of dynamic influences (such as changing environments) then stability should approach an asymptote of zero over greater intervals. Conversely, if personality was only a function of stable influences, then it should be equally stable across all intervals (Fraley \& Roberts, 2005). In our 4-wave longitudinal data, we examined stability at multiple intervals to see whether it declined as a function of interval length.

\section{Change through the Perspective of Self and Others}

Do mean-level change and rank-order stability depend upon whether you ask the person him/herself or others who know the person well? Theoretically, this would depend on the extent to which self- and informant-reports are indicators of the same construct versus distinct constructs. Self-other agreement on personality traits is substantial but not perfect (e.g., Funder, 1980), suggesting that the answer a mix of both. 
The Trait-Reputation-Identity Model (TRIM; McAbee \& Connelly, 2016) holds that selfreports and informant-reports on a given characteristic for a particular target are both affected by that target's underlying trait, but each is also uniquely affected by identity and reputation respectively (extending the socio-analytic model; Hogan, 1996; Hogan \& Roberts, 2004). Accordingly, discrepancies between self-reports and informant-reports may correspond to differences in normative change and rank-order stability of identity and reputation, whereas convergences may correspond to their common basis (i.e., personality traits).

Empirically, studies of mean-level change sometimes find evidence of discrepancies between self- and informant-reports. For instance, mean-level change assessed by informantreports from newly-wedded spouses have been found to show different patterns from self-reports (Watson \& Humrichouse, 2006). More generally however, mean-level change in observer reports are often somewhat weaker and sometimes fail to reach significance, but they are typically in the same direction (Jackson et al., 2009; McCrae et al., 2004). There appear to be no substantial differences in the rank-order stability of self- and informant-reports in either the size or patterning of estimates (Roberts \& DelVecchio, 2000; Watson \& Humrichouse, 2006).

\section{Overview of the Present Study}

In the present study, we examined mean-level change and rank-order stability of personality characteristics in a large longitudinal study. As a preliminary step, we first examined measurement invariance across age groups, which is necessary for making valid comparisons across different ages (Gregorich, 2006). Next, we examined mean-level change in the Big Six personality domains. In doing so, we report the first evidence of mean-level change in HonestyPropriety, testing a novel prediction derived from the maturity principle. We also analyzed change at the relatively less studied level of aspects, gender differences in personality change, 
and whether the same patterns are seen across the perspectives of the self and others. Third, we examine rank-order stability, specifically investigating whether the working years plateau is a justifiable modification of the Cumulative Continuity Principle, whether stability is lower at greater retest intervals, and whether patterns of rank-order stability are similar across the perspectives of the self and others.

\section{Method}

The data and code for the analyses presented in this study are all available on the Open Science Framework, and can be found at http://osf.io/2cu8e.

\section{Participants \& Procedure}

We recruited an initial set of 879 participants for a national sample of U.S. adults, all of whom were assessed online. We advertised using a variety of channels (including Amazon Mechanical Turk, Craigslist ads, and marketing email lists). We applied a quota sampling strategy in which prospective participants initially completed a brief screening questionnaire about demographic characteristics and state of residence; we then invited participants from different racial and ethnic groups and areas of the country (dividing the United States into 4 regions) using approximate matching to Census figures to yield a diverse sample. We also screened for age; respondents from ages 18 to 55 at the first wave eligible to participate. Four participants above the age of 55 made it past our initial screening and into the study, but were excluded from all analyses for being above the recruitment cut-off age. This left a total of 875 participants. An additional 15 participants were excluded after an internal consistency check because they provided inconsistent responses to the age question across waves (e.g., impossibly large gaps given the intervals between assessment times), which left 860 participants. Two additional participants did not provide age data, and were thus excluded from analyses. This 
ultimately resulted in $N=858$ participants in the final sample used in all analyses that follow. Participants ranged in age from 18 to 55 , with a mean age of $36.0\left(S D_{\text {Age }}=10.5\right)$. The majority of participants were female (66\% female; we did not apply quota sampling based on gender). Self-reported demographics indicated that $72 \%$ of the sample identified as White or Caucasian, 12\% identified as Black or African-American, 7\% identified as Hispanic, Latino, or Spanish, 5\% identified as Asian or Asian-American, 2\% identified as Native American, and 1\% identified as Hawaiian or Pacific Islander; these responses were not mutually exclusive, so participants could indicate more than one ethnicity.

We followed a cross-sequential design (Schaie, 1965) in which we recruited participants from a large age range at Time 1 (18-55), and administered surveys to these participants at 4 waves, each spaced roughly 1 year apart. This resulted in a maximum of 4 observations for each participant. After the first wave, which took place in 2009, participants were always invited to participate in subsequent waves, even if they had missed a wave. For example, if someone completed Wave 1, and did not complete Wave 2, they would still be invited to participate in Waves 3 and 4. Of the 858 participants, 168 provided complete data for only 1 wave, 99 participants provided complete data for 2 waves, 97 participants provided complete data for 3 waves, and 494 participants provided complete data for all 4 waves.

In order to compare stability of personality traits in different age ranges, we grouped participants into age groups based on decades. Participants aged 18-19 at the first wave were less frequent than other age decades, so we put them into the 20's group. Thus, we had 4 age groups: 18-29, 30-39, 40-49, and 50-55, which comprised 303, 227, 200, and 128 participants respectively at Time 1 .

\section{Informants}


The 858 main participants were each asked to nominate up to six informants to provide informant-reports of the main participant's personality. 594 participants nominated informants at any of the four time points. Of these participants, the majority had either 0,1 , or 2 informants at each wave (see Table 1).

Table 1. Number of Informants at Each Wave

\begin{tabular}{ccccccccc}
\hline Time & \multicolumn{10}{c}{ Number of Informants } \\
\hline & 0 & 1 & 2 & 3 & 4 & 5 & 6 & Total \\
\hline 1 & 172 & 216 & 127 & 48 & 19 & 11 & 1 & 594 \\
2 & 223 & 159 & 111 & 63 & 22 & 13 & 3 & 594 \\
3 & 223 & 159 & 111 & 63 & 22 & 13 & 3 & 594 \\
4 & 264 & 158 & 85 & 68 & 13 & 5 & 1 & 594 \\
\hline
\end{tabular}

\section{Measures}

Self-Report. Participants self-reported their personality by completing the 44-item version of the Big Five Inventory (BFI-44; John, Naumann, \& Soto, 2008) plus additional items covering the Honesty-Propriety domain. The BFI-44 consists of 44 items which measure the Big Five personality domains (i.e., Extraversion, Agreeableness, Conscientiousness, Neuroticism/Emotional Stability, and Openness). The a priori Honesty-Propriety subscale consisted of 8 items; five adapted from a previous measure of the Big Six (48QB6; Thalmayer, Saucier, \& Eigenhuis, 2011) and three additional items (see Supplemental Table S1a). Each of these items was rated on a scale from 1 (disagree strongly) to 5 (agree strongly), with a neutral point of 3 (neither agree nor disagree). Each subscale had adequate internal consistency at each measurement occasion (see Supplemental Table S2 for alphas of each subscale at each measurement occasion). In addition, we measured a modified Agreeableness- 6 factor from the six-factor model (conceptually centered on even-temperedness instead of warmth and compassion) using five items from the 48QB6 and three additional items (see Supplemental 
Table S1b). For continuity with previous literature, we focus on the BFI-44 Agreeableness results in the main text; but for completeness, additional results from the 48QB6-Agreeableness scale are presented in the Supplement.

Participants also completed the Big Five Aspects Scale (BFAS; DeYoung et al., 2007). The BFAS measures two Aspects for each of the Big Five domains. Assertiveness and Enthusiasm are the aspects of Extraversion, Compassion and Politeness are the aspects of Agreeableness, Industriousness and Orderliness are the aspects of Conscientiousness, Volatility and Withdrawal are the aspects of Neuroticism, and Openness and Intellect are the aspects of Openness. Each of the aspect scales contain 10 short statement items (e.g., "have a lot of fun" from the enthusiasm subscale), and each item is rated on a scale from 1 (Extremely Inaccurate) to 5 (Extremely Accurate), with a neutral point of 3 (Neither accurate nor inaccurate). The BFAS subscales also had adequate internal consistency (see Supplemental Table S2).

Informant-Report. Informants completed an informant-report version of the 10 item version of the Big Five Inventory (BFI-10; Rammstedt \& John, 2007), and two items from the 48QB6 covering the Honesty-Propriety domain. The BFI-10 consists of two items for each of the Big Five personality domains. These items are formatted in the same way as the BFI-44. To assess the reliability of informant ratings, we calculated a coefficient of generalizability $\left(\rho^{2}\right.$; see Furr and Funder, 2007) for each of the Big Six. First, we estimated the following model for each of the Big Six using the lme4 (Version 1.1-1.2; Bates, Maechler, Bolker \& Walker, 2014) package in R (Version 3.3.1; R Core Team, 2016):

$$
\text { Rating }_{\mathrm{ijk}}=\theta_{0}+a_{0 \mathrm{i}}+b_{0 \mathrm{j}}+c_{0 \mathrm{k}}+d_{0 \mathrm{ik}}+e_{\mathrm{ijk}}
$$

where $\theta_{0}$ is the grand mean across all informants and targets, $a_{0 \mathrm{i}}$ is the random effect for subjects, $b_{0 \mathrm{j}}$ is the random effect for informants, $c_{0 \mathrm{k}}$ is the random effect for item (contrast coded), $d_{0 \mathrm{jk}}$ is 
the random effect for the subject by item interaction, and $e_{\mathrm{ijk}}$ is the residual error term. We then calculated $\rho^{2}$ for target effects by dividing the variance from the random effect for subject by the sum of the random effects of subject, the subject by item interaction, and the residual variance $\left(\tau_{\mathrm{a} 00}+\tau_{\mathrm{d} 00}+\sigma^{2}\right)$. Coefficients of generalizability can be interpreted as the proportion of variance in ratings that is attributable to individual differences in targets after removing other systematic factors (informants and items). Similar to inter-item or inter-judge correlations, it does not increase with larger numbers of items/judges in the way that coefficient alpha does.

Generalizability coefficients for each trait at each time point are displayed in Table 2. They ranged from a low of $\rho^{2}=.11$ for Openness to a high of $\rho^{2}=.43$ for Neuroticism. For the primary analyses, we took the average rating across available informants for each trait, at each time point.

Table 2. Coefficient of Generalizability for Informant Ratings

\begin{tabular}{lllll}
\hline \multicolumn{1}{c}{ Trait } & Time 1 & Time 2 & Time 3 & Time 4 \\
\hline Agreeableness & 0.18 & 0.24 & 0.32 & 0.31 \\
Conscientiousness & 0.26 & 0.20 & 0.27 & 0.23 \\
Honesty-Propriety & 0.35 & 0.29 & 0.35 & 0.27 \\
Neuroticism & 0.34 & 0.34 & 0.36 & 0.43 \\
Extraversion & 0.37 & 0.32 & 0.35 & 0.40 \\
Openness & 0.11 & 0.14 & 0.21 & 0.16 \\
\hline
\end{tabular}

Note. Coefficients of generalizability were calculated following a modified version of the formula presented in Furr \& Funder (2007).

To aid with interpretations, all self-report and informant-report personality variables were transformed to Percent of Maximum Possible (POMP) scores, which have a theoretical range from 0 to 100 (Cohen, Cohen, Aiken, \& West, 1999). POMP is a linear transformation that does not alter the results of inferential tests, but it results in potentially more interpretable units. 


\section{Attrition and Missing Data}

To check for potentially biasing effects of attrition, we first examined whether Big Six scores, Big Five Aspect scores, or demographic data collected at Time 1 predicted attrition in a series of 19 binary logistic regressions. Demographic data included ethnicity, gender, and two measures of subjective socioeconomic status (SES; Adler \& Stewart, 2007). Of the Big Six, only scores on Openness significantly predicted attrition $(O R=1.01, p=.03,95 \% \mathrm{CI}[1.00,1.02])$, such that a POMP unit increase in Openness scores was associated with 1.01 times greater odds of returning for all 4 time points. Of the 10 BFAS scores, only Intellect significantly predicted attrition $(O R=1.01, p=.005,95 \%$ CI $[1.00,1.02])$, such that a POMP unit increase in intellect was associated with 1.01 times greater odds of returning for all 4 time points. As can be seen from the point estimate and confidence interval, the effects of Openness and its Intellect aspect on attrition, while significant, are quite small. We found no difference in attrition attributable to gender or the two indicators of self-reported SES. Because ethnicity consisted of 6 categories, we entered 5 dummy codes into a binary logistic regression predicting attrition. Participants who identified as Native American were significantly less likely to return to future measurement occasions $(O R=.29, p=.04,95 \% \mathrm{CI}[.08, .88])$; there were no other differences in attrition attributable to self-reported ethnicity.

Note, however, that across the 19 logistic regressions, 24 parameters were tested: 6 BFI scores, 10 BFAS scores, 2 SES scores, 1 gender dummy code, and 5 dummy codes for ethnicity. The 3 significant predictors of attrition, overall Openness scores at Time 1, Intellect scores at Time 1, and identifying as a Native American, all have relatively small effect sizes. Taken together, there does not appear to be substantial personality- or demographic-based bias in attrition. As such, we treated all missing data with full information maximum likelihood (FIML), 
which is unbiased assuming the data are MAR (Enders \& Bandalos, 2001). To do this, we used the FIML option in the Lavaan package (Version .50-2; Rosseel, 2012) in R and in Mplus (version 7.31; Muthén \& Muthén, 1998-2012).

\section{Results}

Our results begin with preliminary analyses of measurement models of self-reported personality traits, with a goal of evaluating measurement invariance. We were unable to test measurement models for informant reports due to the constraints of the data (i.e., only two items per trait). After these preliminary analyses, we report our main analyses using the measurement models that we tested in the preliminary analyses.

\section{Preliminary Analyses of Measurement Invariance}

Before assessing stability and mean-level change, we first tested whether or not our selfreport measures of the Big Six and Big Five Aspects show measurement invariance across age groups. All of the substantive analyses (i.e., mean-level change and stability) are conducted on factor means, factor variances, and factor covariances (rather than observed means, variances, and covariances). These analyses thus only require scalar invariance (i.e., equal loadings and equal intercepts) across age groups in order to substantively interpret age group differences. However, we went beyond scalar invariance to test strict factorial invariance (equal loadings, item intercepts, and residuals; Gregorich, 2006), since that may be of interest beyond our immediate questions here (e.g., for researchers who use these scales in observed-variable analyses). In order to test for measurement invariance, we first fit the appropriate measurement models, and then compared them using both absolute and relative fit indices. To the extent that measurement properties are similar (i.e., invariant) across age groups, we would find that the more constrained measurement models fit the data equally well as the less constrained models. 
In order to fit measurement models to self-reported personality, we first created three parcels of items for each of the Big Six domains, and each of the 10 aspects from the BFAS. The BFI-44 with the additional $6^{\text {th }}$ domain items had between eight and ten items per subscale, so each of the parcels for the factor scores had between two and four items. The BFAS has 10 items per subscale, so each of the parcels for BFAS scores had either three or four items. We created parcels by using the domain-representative approach (Little, Cunningham, Shahar, \& Widaman, 2002). Specifically, we conducted a Principal Components Analysis (PCA) in the Psych package in R (version 1.6.4; Revelle, 2016) on the items from each of the subscales and extracted three components, and created parcels such that each contained items from all three domains. This general procedure was followed for each of the subscales of the Big Six and BFAS.

We next specified two measurement models per personality factor using Lavaan. We specified multiple-groups models with each age group as one group. Model 1 imposed strict measurement invariance across the different waves within each age group (i.e., longitudinal invariance), but allowed models to differ between age groups. Model 2 imposed strict measurement invariance across age groups (cross-sectional invariance; Gregorich, 2006). Thus, the model comparison indicates whether there is measurement invariance between the decadebased age groups. An example of the first model is presented in Figure 1. Further details of the invariance analysis are provided in the Supplement.

Did we find evidence of strict measurement invariance across age groups? In short, yes: we found very small decrements of fit produced from imposing strict measurement invariance. Table 3 displays several model fit indices for the two measurement models. As can be seen in Table 3, the Chi-Square difference test was significant for most of the Big Six personality domains and Big Five aspects. However, the significant Chi-Square difference tests provide only 


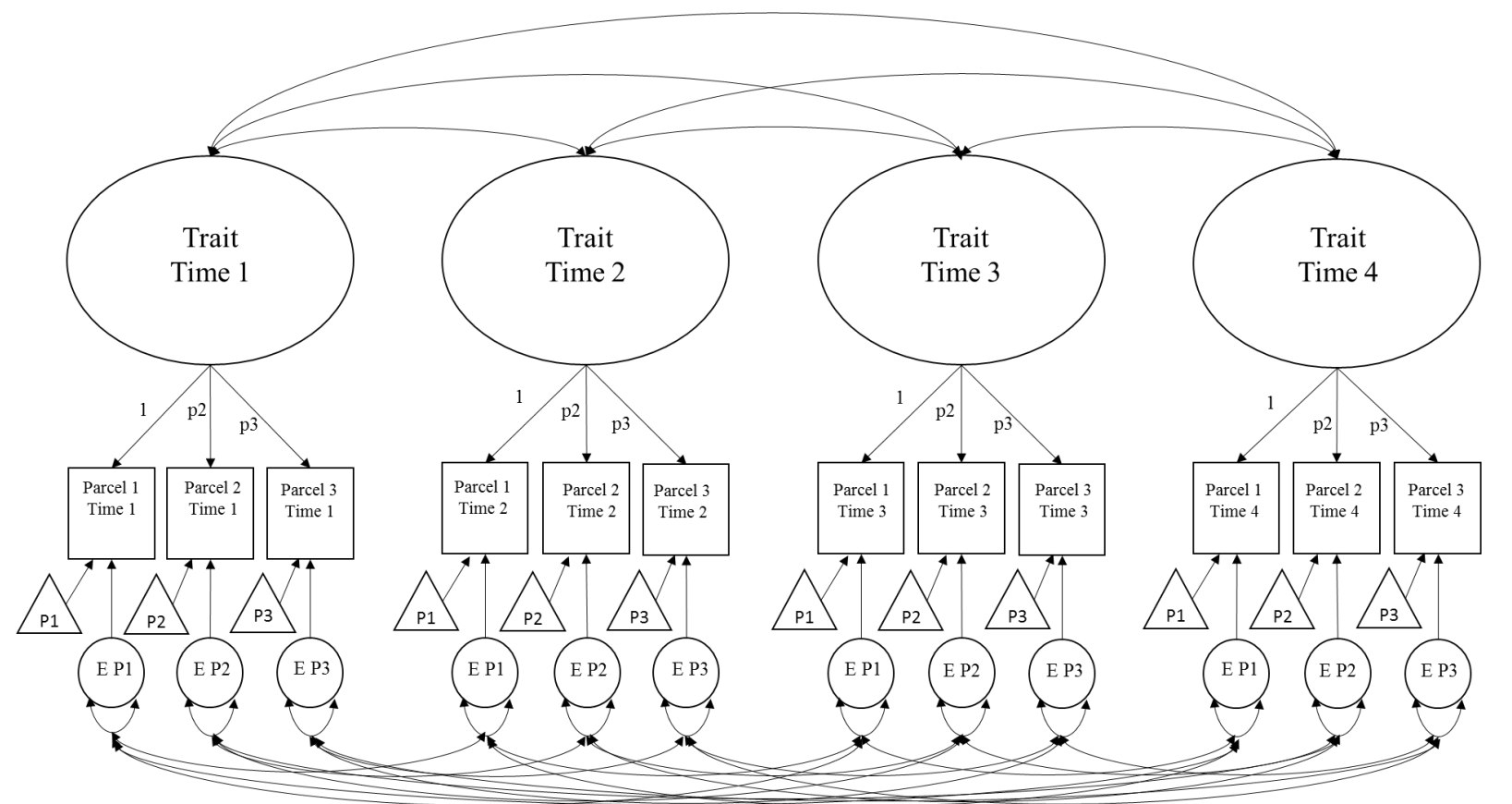

Figure 1. Measurement Models fit for each of the Big Six Personality Factors and Big Five Aspects. The paths with the same letter were constrained to be equal, as were the error variances and intercepts that have the same name. The covariances between the same parcels at different times were also constrained to be equal, but this is not displayed above. 
Table 3. Model Fit Indices for Measurement Invariance Tests

\begin{tabular}{|c|c|c|c|c|c|c|}
\hline Trait & Invariance & $d f$ & AIC & $\mathrm{BIC}$ & $\chi^{2}$ & RMSEA $[90 \% \mathrm{CI}]$ \\
\hline \multirow[t]{2}{*}{ Agreeableness } & None & 276 & 12544.72 & 12944.10 & 280.88 & $.009[.000, .029]$ \\
\hline & Strict Factorial & 309 & 12558.62 & 12801.11 & $360.78 * * *$ & $.028[.011, .039]$ \\
\hline \multirow[t]{2}{*}{ Compassion } & None & 276 & 10178.78 & 10578.17 & 393.07 & $.044[.033, .055]$ \\
\hline & Strict Factorial & 309 & 10160.05 & 10402.54 & 440.34 & $.045[.033, .054]$ \\
\hline \multirow[t]{2}{*}{ Politeness } & None & 276 & 12699.08 & 13098.47 & 345.21 & $.034[.021, .045]$ \\
\hline & Strict Factorial & 309 & 12701.44 & 12943.92 & $413.57 * * *$ & $.040[.029, .049]$ \\
\hline \multirow[t]{2}{*}{ Conscientiousness } & None & 276 & 12466.10 & 12865.49 & 343.98 & $.034[.020, .045]$ \\
\hline & Strict Factorial & 309 & 12468.25 & 12710.74 & $412.13 * * *$ & $.039[.029, .049]$ \\
\hline \multirow[t]{2}{*}{ Industriousness } & None & 276 & 12510.62 & 12910.01 & 327.41 & $.029[.013, .041]$ \\
\hline & Strict Factorial & 309 & 12510.83 & 12753.31 & $393.62 * *$ & $.036[.024, .046]$ \\
\hline \multirow[t]{2}{*}{ Orderliness } & None & 276 & 12943.92 & 13343.30 & 368.77 & $.040[.028, .050]$ \\
\hline & Strict Factorial & 309 & 12924.67 & 13167.16 & 415.53 & $.040[.029, .050]$ \\
\hline \multirow{2}{*}{ Honesty-Propriety } & None & 276 & 14236.43 & 14635.82 & 347.63 & $.035[.022, .046]$ \\
\hline & Strict Factorial & 309 & 14245.11 & 14487.60 & $422.31 * * *$ & $.041[.031, .051]$ \\
\hline \multirow[t]{2}{*}{ Neuroticism } & None & 276 & 15053.62 & 15453.00 & 325.12 & $.029[.012, .041]$ \\
\hline & Strict Factorial & 309 & 15075.38 & 15317.87 & $412.88 * * *$ & $.040[.029, .049]$ \\
\hline \multirow[t]{2}{*}{ Withdrawal } & None & 276 & 13588.06 & 13987.45 & 351.421 & $.036[.023, .046]$ \\
\hline & Strict Factorial & 309 & 13575.37 & 13817.86 & $404.733 *$ & $.038[.027, .048]$ \\
\hline \multirow[t]{2}{*}{ Volatility } & None & 276 & 13824.95 & 14224.33 & 301.13 & $.021[.000, .035]$ \\
\hline & Strict Factorial & 309 & 13815.94 & 14058.43 & $358.12 * *$ & $.027[.010, .039]$ \\
\hline \multirow[t]{2}{*}{ Extraversion } & None & 276 & 13592.95 & 13992.34 & 301.36 & $.021[.000, .035]$ \\
\hline & Strict Factorial & 309 & 13581.08 & 13823.57 & $355.49 *$ & $.026[.008, .038]$ \\
\hline \multirow[t]{2}{*}{ Assertiveness } & None & 276 & 11981.25 & 12380.64 & 352.59 & $.036[.023, .047]$ \\
\hline & Strict Factorial & 309 & 11990.80 & 12233.29 & $428.14 * * *$ & $.042[.032, .052]$ \\
\hline \multirow[t]{2}{*}{ Enthusiasm } & None & 276 & 12507.64 & 12907.02 & 315.94 & $.026[.002, .039]$ \\
\hline & Strict Factorial & 309 & 12491.53 & 12734.02 & $365.85^{*}$ & $.029[.014, .041]$ \\
\hline \multirow[t]{2}{*}{ Openness } & None & 276 & 11322.37 & 11721.76 & 408.29 & $.047[.037, .057]$ \\
\hline & Strict Factorial & 309 & 11316.79 & 11559.27 & $468.70 * *$ & $.049[.040, .058]$ \\
\hline \multirow[t]{2}{*}{ Intellect } & None & 276 & 11172.40 & 11571.78 & 403.32 & $.046[.036, .056]$ \\
\hline & Strict Factorial & 309 & 11187.20 & 11429.69 & $484.13 * * *$ & $.051[.042, .060]$ \\
\hline \multirow[t]{2}{*}{ Openness } & None & 276 & 11838.84 & 12238.23 & 351.25 & $.036[.023, .046]$ \\
\hline & Strict Factorial & 309 & 11822.92 & 12065.40 & $401.33^{*}$ & $.037[.026, .047]$ \\
\hline
\end{tabular}

Note. ${ }^{*}=\mathrm{p}<.05 ; * *=\mathrm{p}<.01 ; * * * \mathrm{p}<.001 . p$ values refer to Chi-Square difference test between the two measurement models. Aspects from the BFAS are indented. 
weak evidence against the null hypothesis of perfect measurement invariance; between the large sample size $(N=858)$ and the fairly large difference in parsimony (i.e., an addition of 33

parameters in the non-invariance model) even trivial increases in fit can lead to a significant ChiSquare value. Indeed, inspecting the parsimony-adjusted fit indices, AIC and BIC, suggests that the model with measurement invariance fits the data better for all of the Big Six and all of the Big Five Aspects (see Table 3). More specifically, AIC was lower (i.e., better) for many of the measurement invariance models, and BIC is lower (i.e., better) for all of the measurement invariance models, which suggests that small loss in fit is worth the gain in parsimony. Further evidence of measurement invariances comes from the similar RMSEA values between invariance and non-invariance models. The largest difference in RMSEA, Agreeableness, is still an increase of only .019 from the invariance constraints, and the Confidence Intervals around these estimates overlap substantially. Finally, dividing the Chi-Square values by their associated degrees of freedom results in similar values for the non-invariance models (1.02 to 1.48) and invariance models (1.15 to 1.57$)$. We thus retained the measurement models that impose strict measurement invariance for both the mean-level change and stability analyses on self-reported Big Six personality domains and Big Five Aspects.

\section{Mean-Level Change}

Self-report. To estimate mean-level change in each of the personality variables, we fit a curve-of-factors model (Duncan \& Duncan, 1996), in which two growth parameters, a latent slope and latent intercept, are fitted to latent variables rather than observed variables, retaining the measurement models evaluated previously. Loadings for latent slopes were set using "T scores” in Mplus version 7.31 (Muthén \& Muthén, 1998-2012), in which each individual's grand mean-centered ages were used for that individual's loadings of the latent slope. This model was 
fit with a random-effects structural equation model, which is necessary when using $\mathrm{T}$ scores. The estimates and CIs for all of the Big Six and BFAS models can be found in Table 4 and Table 5 respectively. Figure 2 contains plots of mean-level change for the Big Six, and Figure 3 contains plots of mean-level change for the three Big Five Aspects where there were gender differences in change. Plots of mean-level change in the remaining Big Five Aspects can be found in the supplement (see Supplemental Figure S1).

Evaluating the Maturity Principle. The maturity principle, as originally stated, suggests that we should see mean-level increases in Conscientiousness, Agreeableness, and mean-level decreases in Neuroticism. We found support for all three predictions. As can be seen in Figure 2, we found mean-level increases in Conscientiousness $(b=0.18, p<.001,95 \%$ CI $[0.09,0.27])$ and Agreeableness $(b=0.26, p<.001,95 \%$ CI $[0.15,0.36])$ and decreases in Neuroticism $(b=$ $0.19, p=.001,95 \%$ CI $[-0.29,-0.08])$. To aid in interpretation, we created a standardized mean difference metric to quantify average change over 10 years. To do this, we multiplied the slope estimates by 10 and divided by the intercept standard deviations. This produced a standardized effect size estimate that compares change over time to the amount of latent variability in individual differences in a trait, which we labeled $d_{10}$. For example, for Conscientiousness the coefficient of $b=0.18$ means that an average person increased by 1.8 unstandardized scale units per decade. Dividing that by the intercept standard deviation of 12.5 indicates that the average level of conscientiousness increased by $d_{10}=0.14$ ( 0.14 SDs per decade). The analogous estimates were $d_{10}=0.19$ for Agreeableness and $d_{10}=-0.13$ for Neuroticism. Using Cohen's rules of thumb for interpreting standardized mean differences, these were small effects, though our choice of a decade for these interpretive numbers was arbitrary (the numbers would be doubled or tripled for change over 20 or 30 years respectively). 
Table 4. Curve of Factors Model Parameters for Self-Report Big Five and Honesty-Propriety

\begin{tabular}{|c|c|c|c|c|c|}
\hline Trait & Parameter & Estimate & $d_{10}$ & $95 \% \mathrm{CI}$ & $p$ \\
\hline \multirow[t]{5}{*}{ Agreeableness } & Gender & -4.01 & & {$[-6.22,-1.80]$} & $<.001$ \\
\hline & Linear Slope & 0.26 & 0.19 & {$[0.15,0.36]$} & $<.001$ \\
\hline & Gender X Slope & -0.03 & -0.02 & {$[-0.23,0.17]$} & .754 \\
\hline & Intercept Variance & 181.16 & & {$[150.42,217.90]$} & $<.001$ \\
\hline & Slope Variance & 0.16 & & {$[-0.08,0.39]$} & .198 \\
\hline \multirow[t]{5}{*}{ Conscientiousness } & Gender & -3.28 & & {$[-5.30,-1.26]$} & .001 \\
\hline & Linear Slope & 0.18 & 0.14 & {$[0.09,0.27]$} & $<.001$ \\
\hline & Gender X Slope & -0.08 & -0.06 & {$[-0.24,0.08]$} & .347 \\
\hline & Intercept Variance & 155.75 & & {$[132.57,178.93]$} & $<.001$ \\
\hline & Slope Variance & 0.00 & & {$[0.00,0.00]$} & .965 \\
\hline \multirow[t]{5}{*}{ Honesty-Propriety } & Gender & -7.36 & & {$[-9.43,-5.29]$} & $<.001$ \\
\hline & Linear Slope & 0.31 & 0.27 & {$[0.21,0.40]$} & $<.001$ \\
\hline & Gender X Slope & 0.06 & 0.05 & {$[-0.13,0.25]$} & .524 \\
\hline & Intercept Variance & 128.13 & & {$[99.95,156.31]$} & $<.001$ \\
\hline & Slope Variance & 0.09 & & {$[-0.07,0.25]$} & .264 \\
\hline \multirow[t]{5}{*}{ Neuroticism } & Gender & -6.39 & & {$[-8.75,-4.02]$} & $<.001$ \\
\hline & Linear Slope & -0.19 & -0.13 & {$[-0.29,-0.08]$} & .001 \\
\hline & Gender X Slope & 0.30 & 0.21 & {$[0.09,0.52]$} & .006 \\
\hline & Intercept Variance & 209.93 & & {$[176.64,243.23]$} & $<.001$ \\
\hline & Slope Variance & 0.13 & & {$[-0.06,0.32]$} & .181 \\
\hline \multirow[t]{5}{*}{ Extraversion } & Gender & -1.77 & & {$[-4.37,0.83]$} & .181 \\
\hline & Linear Slope & 0.12 & 0.07 & {$[0.001,0.23]$} & .047 \\
\hline & Gender X Slope & -0.06 & -0.04 & {$[-0.29,0.18]$} & .634 \\
\hline & Intercept Variance & 271.76 & & {$[234.61,308.92]$} & $<.001$ \\
\hline & Slope Variance & 0.29 & & {$[0.06,0.52]$} & .014 \\
\hline \multirow[t]{5}{*}{ Openness } & Gender & 1.08 & & {$[-0.75,2.91]$} & .247 \\
\hline & Linear Slope & -0.17 & -0.14 & {$[-0.25,-0.08]$} & $<.001$ \\
\hline & Gender X Slope & -0.11 & -0.09 & {$[-0.29,0.06]$} & .197 \\
\hline & Intercept Variance & 137.74 & & {$[116.45,159.02]$} & $<.001$ \\
\hline & Slope Variance & 0.09 & & {$[-0.07,0.25]$} & .276 \\
\hline
\end{tabular}

Note. Gender was contrast coded (Men $=.5$; Women $=-.5)$. The Latent Intercept is not displayed in the above table because it was constrained to be equal to zero in all of the above models; this constraint is common in Curve of Factors Models. Gender is the gender difference in the intercept. Gender X Slope is the gender difference in the slope. Estimate is the unstandardized parameter estimate. $d_{10}$ is the estimate divided by the standard deviation (square root of the intercept variance), multiplied by ten; it corresponds to the change in mean levels per decade relative to between-person standard deviation units. 
Table 5. Curve of Factors Model Parameters for Self-Report Big Five Aspects

\begin{tabular}{|c|c|c|c|c|c|}
\hline Trait & Parameter & Estimate & $d_{10}$ & $95 \% \mathrm{CI}$ & $p$ \\
\hline \multirow[t]{5}{*}{ Compassion } & Gender & -8.03 & & {$[-10.16,-5.91]$} & $<.001$ \\
\hline & Linear Slope & 0.12 & 0.10 & {$[0.02,0.22]$} & .014 \\
\hline & Gender X Slope & -0.11 & -0.09 & {$[-0.31,0.08]$} & .244 \\
\hline & Intercept Variance & 145.81 & & {$[118.32,173.30]$} & $<.001$ \\
\hline & Slope Variance & 0.14 & & {$[-0.07,0.35]$} & .194 \\
\hline \multirow[t]{5}{*}{ Politeness } & Gender & -8.26 & & {$[-10.41,-6.11]$} & $<.001$ \\
\hline & Linear Slope & 0.31 & 0.24 & {$[0.21,0.41]$} & $<.001$ \\
\hline & Gender X Slope & 0.01 & 0.01 & {$[-0.19,0.21]$} & .926 \\
\hline & Intercept Variance & 171.34 & & {$[143.63,199.05]$} & $<.001$ \\
\hline & Slope Variance & 0.15 & & {$[-0.05,0.35]$} & .152 \\
\hline \multirow[t]{5}{*}{ Industriousness } & Gender & -1.27 & & {$[-3.54,1.01]$} & .276 \\
\hline & Linear Slope & 0.17 & 0.12 & {$[0.07,0.27]$} & .001 \\
\hline & Gender X Slope & -0.12 & -0.09 & {$[-0.33,0.09]$} & .250 \\
\hline & Intercept Variance & 198.91 & & {$[167.70,230.11]$} & $<.001$ \\
\hline & Slope Variance & 0.12 & & {$[-0.09,0.33]$} & .275 \\
\hline \multirow[t]{5}{*}{ Orderliness } & Gender & -4.82 & & {$[-6.98,-2.66]$} & $<.001$ \\
\hline & Linear Slope & 0.09 & 0.07 & {$[-0.01,0.18]$} & .082 \\
\hline & Gender X Slope & 0.11 & 0.09 & {$[-0.09,0.30]$} & .288 \\
\hline & Intercept Variance & 157.22 & & {$[122.96,191.47]$} & $<.001$ \\
\hline & Slope Variance & 0.20 & & {$[-0.01,0.41]$} & .063 \\
\hline \multirow[t]{5}{*}{ Withdrawal } & Gender & -4.76 & & {$[-7.71,-1.81]$} & $<.001$ \\
\hline & Linear Slope & -0.23 & -0.13 & {$[-0.37,-0.09]$} & .026 \\
\hline & Gender X Slope & 0.33 & 0.18 & {$[0.06,0.60]$} & $<.001$ \\
\hline & Intercept Variance & 333.61 & & {$[285.30,381.93]$} & $<.001$ \\
\hline & Slope Variance & 0.32 & & {$[-0.04,0.67]$} & .078 \\
\hline \multirow[t]{5}{*}{ Volatility } & Gender & -5.41 & & {$[-8.24,-2.58]$} & .002 \\
\hline & Linear Slope & -0.15 & -0.08 & {$[-0.28,-0.02]$} & .001 \\
\hline & Gender X Slope & 0.61 & 0.34 & {$[0.34,0.87]$} & .017 \\
\hline & Intercept Variance & 322.50 & & {$[275.57,371.42]$} & $<.001$ \\
\hline & Slope Variance & 0.28 & & {$[-0.04,0.61]$} & .085 \\
\hline
\end{tabular}

Table 5 continues on next page... 
Table 5 continued...

\begin{tabular}{llrcrr}
\hline \multicolumn{1}{c}{ Trait } & \multicolumn{1}{c}{ Parameter } & Estimate & $d_{10}$ & $95 \%$ CI & $p$ \\
\hline Assertiveness & Gender & 2.39 & & {$[0.01,4.76]$} & .049 \\
& Linear Slope & -0.01 & -0.01 & {$[-0.11,0.10]$} & .907 \\
& Gender X Slope & -0.23 & -0.15 & {$[-0.44,-0.02]$} & .030 \\
& Intercept Variance & 240.07 & & {$[204.15,275.99]$} & $<.001$ \\
& Slope Variance & 0.10 & & {$[-0.12,0.31]$} & .375 \\
Enthusiasm & Gender & -3.13 & & {$[-5.35,-0.91]$} & .006 \\
& Linear Slope & 0.01 & 0.01 & {$[-0.09,0.11]$} & .831 \\
& Gender X Slope & -0.14 & -0.10 & {$[-0.34,0.06]$} & .161 \\
& Intercept Variance & 204.21 & & {$[172.20,236.23]$} & $<.001$ \\
& Slope Variance & 0.03 & & {$[-0.13,0.20]$} & .689 \\
& Gender & 2.22 & & {$[0.30,4.14]$} & .023 \\
& Linear Slope & -0.06 & -0.05 & {$[-0.15,0.03]$} & .164 \\
& Gender X Slope & -0.06 & -0.05 & {$[-0.24,0.11]$} & .469 \\
& Intercept Variance & 133.36 & & {$[110.38,156.33]$} & $<.001$ \\
& Slope Variance & 0.10 & & {$[-0.05,0.26]$} & .196 \\
& Gender & -3.88 & & {$[-5.95,-1.81]$} & $<.001$ \\
Openness & Linear Slope & -0.09 & -0.07 & {$[-0.19,0.00]$} & .056 \\
& Gender X Slope & -0.14 & -0.11 & {$[-0.32,0.04]$} & .127 \\
& Intercept Variance & 162.57 & & {$[130.07,195.06]$} & $<.001$ \\
& Slope Variance & 0.04 & & {$[-0.14,0.22]$} & .675 \\
\hline
\end{tabular}

Note. Gender was contrast coded (Men $=.5$; Women $=-.5$ ). The Latent Intercept is not displayed in the above table because it was constrained to be equal to zero in all of the above models; this constraint is commonly used in Curve of Factors Models. Gender is the gender difference in the intercept. Gender X Slope is the gender difference in the slope. Estimate is the unstandardized parameter estimate. $d_{10}$ is the estimate divided by the standard deviation (square root of the intercept variance), multiplied by ten; it corresponds to the change in mean levels per decade relative to between-person standard deviation units. 

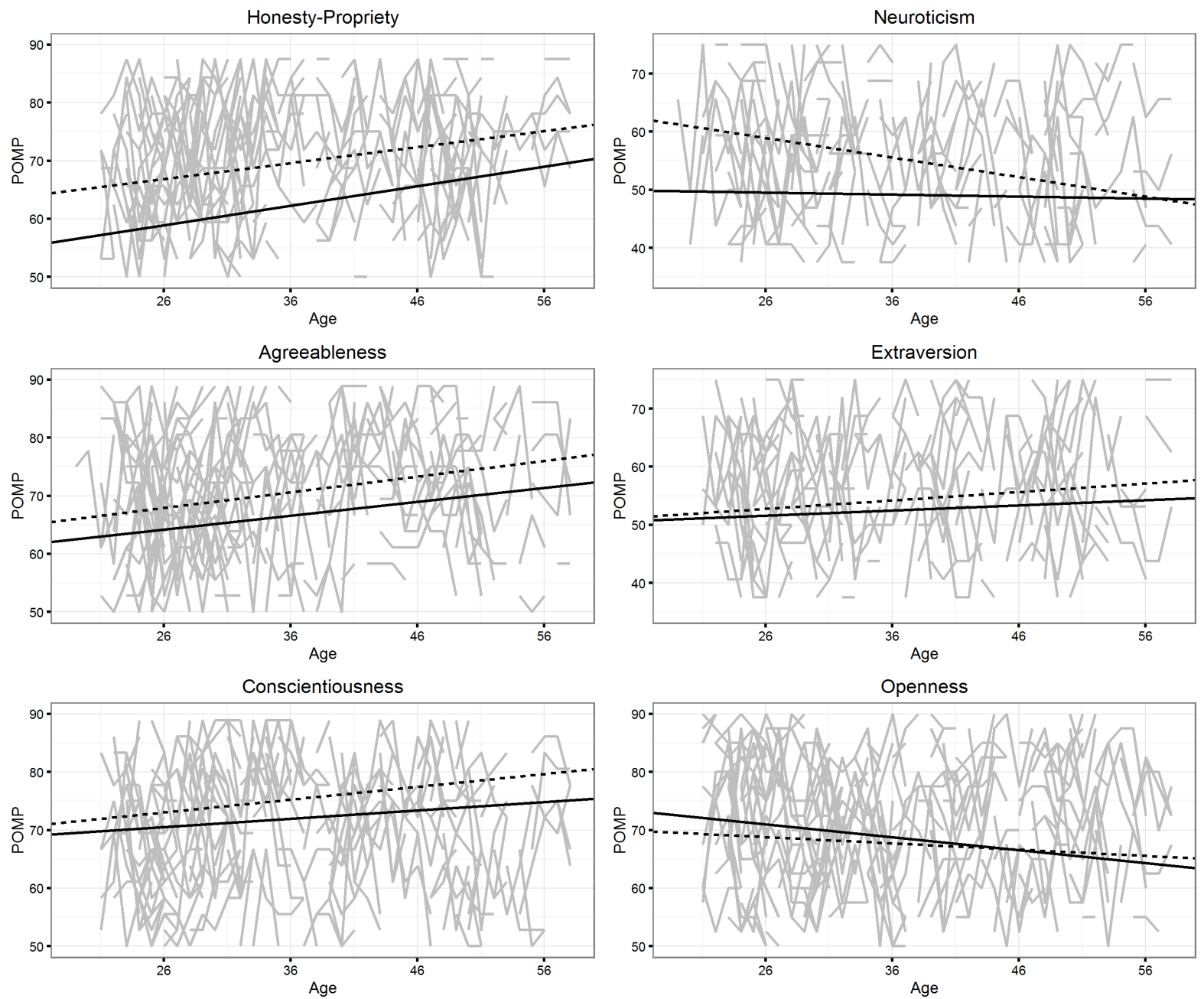

Gender
$\because$ Men
$\therefore$ Women

Figure 2. Mean-Level Change in Self-Reports of Big Six. Fit lines were constructed based on results from Curve of Factors Models. The grey lines in the background correspond to 300 individual participants' scores across the four time points. 

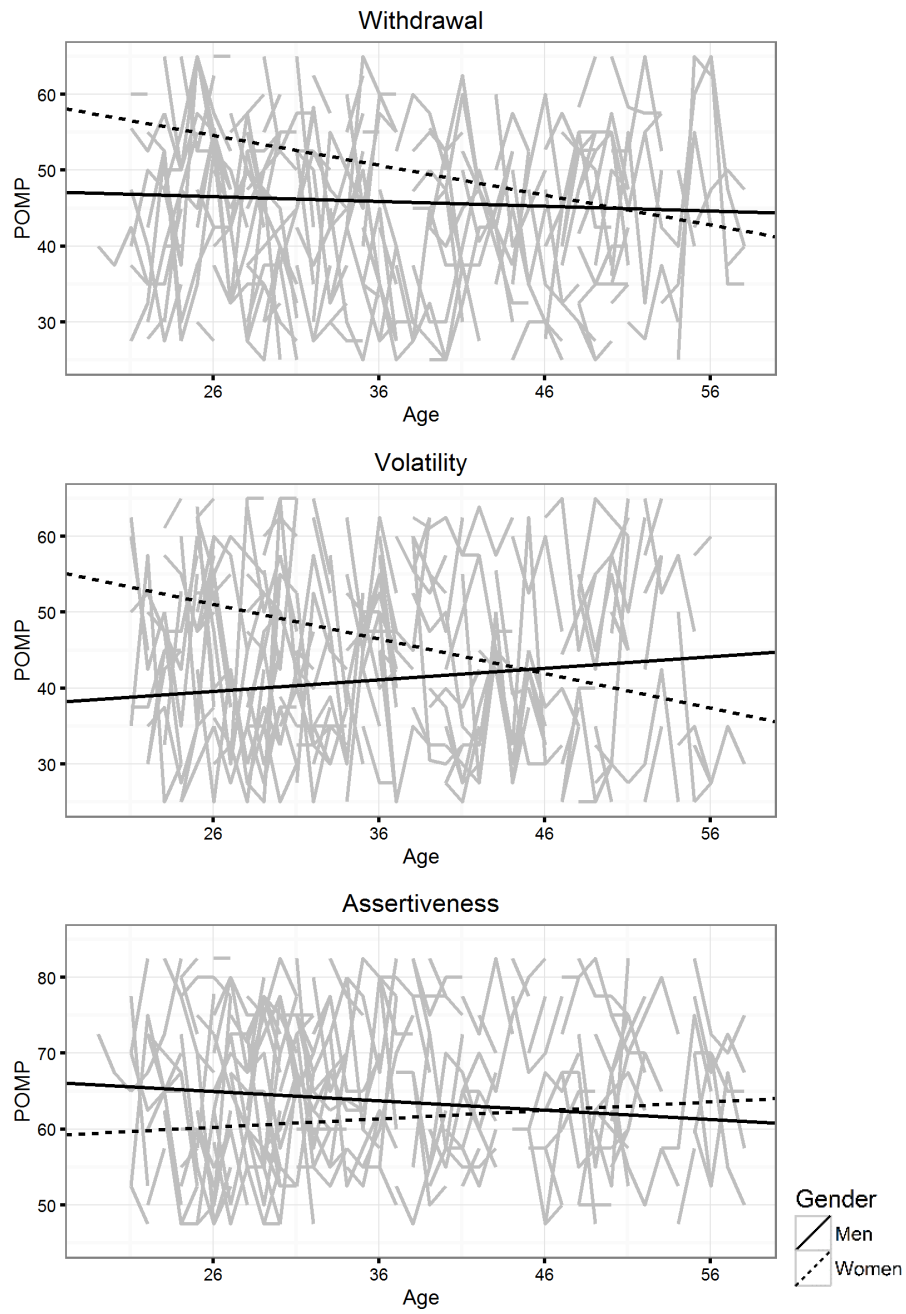

Figure 3. Mean-Level Change in Aspects with Gender Differences in Slopes. Fit lines were constructed based on results from Growth Curve Models. The grey lines in the background correspond to 300 individual participants' scores across the four time points. 
For Honesty-Propriety, the novel test of the maturity principle, we found evidence of mean-level increases $\left(b=0.31, p<.001,95 \%\right.$ CI $[0.21,0.40], d_{10}=0.27$; see Figure 2$)$, indicating that people become more honest and rule-abiding as they age. In standard deviation units this was an increase of 0.27 SDs per decade. Taken together, we replicated previous evidence and found novel evidence consistent with the maturity principle.

The maturity principle does not make claims about changes in the overall domains of Extraversion and Openness. However, we did find small but significant change in both; people tended to decrease in Openness and increase in Extraversion (see Table 4 and Figure 2).

Change in Big Five aspects. We found stronger evidence of mean-level change in one of the aspects of Conscientiousness. Industriousness significantly increased with age $(b=0.17, p=$ $\left..001,95 \% \mathrm{CI}[0.07,0.27], d_{10}=0.12\right)$; Orderliness showed a non-significant, but directionally similar, pattern $\left(b=0.09, p=.082,95 \%\right.$ CI $\left.[-0.01,0.18], d_{10}=0.07\right)$. This is consistent with previous work showing that orderliness is the aspect of Conscientiousness that shows the weakest evidence of normative change (Jackson et al., 2009; Soto et al., 2011). Aspects of Extraversion showed little to no evidence of change, which is at odds with results from the overall domain; this includes Assertiveness $\left(b=-0.01, p=.907,95 \%\right.$ CI $[-0.11,0.10], d_{10}=-$ 0.01), which is at odds with the previous finding that Social Dominance increases with age (Roberts et al., 2006). A similar pattern was observed for Openness and its aspects; the aspects showed no change unlike the broader domain (see Table 5). It is possible that analyses with the BFI (used to measure the overall domain in this study) are picking up on changes in aspects of Extraversion and Openness not captured by the BFAS, leading to the observed discrepancies. Specifically, the Extraversion subscale of the BFI contains two items on talkativeness, which is not covered by the BFAS. Likewise, the Openness subscale of the BFI focuses on curiosity and 
imaginativeness, which are not a focus of either aspect in the BFAS. Aspects of Agreeableness and Neuroticism were consistent with change at the broader domain level.

Gender differences. Did men and women differ in mean levels or in the rate of change for Neuroticism? In order to assess this, we regressed the latent intercept and slope onto a contrast code for gender, where men were coded as +0.5 and women were coded as -0.5 . Women were relatively higher than men in Neuroticism at earlier ages; this can be seen by the significant gender difference in the intercept for Neuroticism $(b=-6.39, p<.001,95 \%$ CI $[-8.75,-4.02])$. Because age was mean-centered, this difference should be interpreted at the sample mean age of 36. Additionally, the comparison of slopes indicated that women decreased in Neuroticism more than men $\left(b=0.30, p=.006,95 \%\right.$ CI $\left.[0.09,0.52], d_{10}=0.21\right)$, which is consistent with previous research (e.g., Soto et al., 2011; Srivastava et al., 2003). Moreover, a test of simple slopes revealed that the slope was significant for women $\left(b=-0.34, p<.001,95 \% \mathrm{CI}[-0.46,-0.21], d_{10}\right.$ $=-0.23)$ but not for men $\left(b=-0.03, p=.715,95 \%\right.$ CI $\left.[-0.21,0.15], d_{10}=-0.02\right)$. Inspecting Figure 2 suggests that this combination led to women and men having similar levels of Neuroticism in middle-adulthood.

Turning to Agreeableness, we see gender differences in the intercept $(b=-4.01, p<.001$, $95 \%$ CI $[-6.22,-1.80])$, but no gender differences in the slope $(b=-0.03, p=.754,95 \%$ CI [0.23, 0.17], $\left.d_{10}=-0.02\right)$. This indicates that women were higher on Agreeableness than men at the sample's average age of 36, and that both men and women increased in Agreeableness at about the same rate. A similar pattern was seen for both Conscientiousness and HonestyPropriety, with significant gender differences in the intercepts but not the slopes (see Table 4 and Figure 2). There were no substantial gender differences in the domains of Extraversion or Openness. 
Gender differences among aspects. We investigated gender differences in Big Five aspects by regressing the slope and intercept of each on a contrast code for gender in the same manner as the broader domains. Model parameters for all aspects are available in Table 5, and aspects with gender differences in slopes are depicted in Figure 3. We expected gender differences in aspects to generally conform to their broader domains. This expectation was only partially supported for Neuroticism. Withdrawal, like the broader domain of Neuroticism, showed evidence of gender differences in both the intercept $(b=-4.76, p<.001,95 \%$ CI $[-7.71$, $-1.81])$ and slope $\left(b=0.33, p<.001,95 \% \mathrm{CI}[0.06,0.60], d_{10}=0.18\right)$ such that women were higher than men on average at the sample mean age, but women showed greater declines over time than men (see Figure 3). Like the broader domain of Neuroticism, tests of simple slopes revealed a significant slope for women $\left(b=-0.39, p<.001,95 \%\right.$ CI $\left.[-0.55,-0.24], d_{10}=-0.21\right)$ but not for men $\left(b=-0.06, p=.588,95 \%\right.$ CI $\left.[-0.29,0.16], d_{10}=-0.03\right)$. Consistent with the broader domain of Neuroticism, we found that women had a higher intercept than men on Volatility $(b=-5.41, p=.002,95 \%$ CI $[-8.24,-2.58])$, and a significant difference in the slope of Volatility $\left(b=0.61, p=.017,95 \%\right.$ CI $\left.[0.34,0.87], d_{10}=0.34\right)$. However, while women decreased in Volatility with age $\left(b=-0.46, p<.001,95 \%\right.$ CI $\left.[-0.61,-0.30], d_{10}=-0.26\right)$, men showed small but non-significant increases in Volatility with age $(b=0.15, p=.17,95 \%$ CI [0.07, 0.37], $d_{10}=0.08$; see Figure 3).

Mirroring the broader domain of Agreeableness, women had higher intercepts for both Politeness and Compassion and there was no evidence of gender differences in the slopes of either aspect (see Table 5). Consistent with the overall domain of Conscientiousness, women had a higher intercept on Orderliness and there was no evidence of gender differences in its slope. Unlike the overall domain of Conscientiousness, there was little to no evidence of gender 
differences in the intercept of Industriousness; there were also no gender differences in the slope for Industriousness (see Table 5). Unlike the broader domain of Extraversion, which showed no gender differences, women had a higher intercept than men on Enthusiasm, whereas men had a higher intercept than women on Assertiveness (see Table 5). The opposite direction of these gender differences may explain the discrepancy with the broader domain, as these may cancel each other out at the domain level. It seems that while women are lower than men on Assertiveness at earlier ages (i.e., lower intercept), they seem to show small non-significant increases with age $\left(b=0.11, p=.085,95 \%\right.$ CI $\left.[-0.02,0.24], d_{10}=0.07\right)$, while men show small non-significant decreases with age $\left(b=-0.12, p=.152,95 \%\right.$ CI $[-0.29,0.05], d_{10}=-0.08$; see Figure 3 and Table 5). Unlike the broader domain of Openness, there was evidence of gender differences in the intercepts, but not the slopes, of both Intellect and Openness (see Table 5). These were in opposite directions: men had higher intercepts than women on Intellect while women had higher intercepts on Openness; like Extraversion, these may cancel each other out at the level of the broader domain.

Informant-Reports. In order to investigate mean-level change in informant-reports of personality, we fit latent growth curve models, in which a latent slope and latent intercept are fitted to the observed average of both items from all available informants at each time-point. (Because the informant reports used only 2 items per scale and the modal number of informants was 1, we did not fit curve-of-factors models to informant data.) Loadings for latent slopes were again set using “T scores” in Mplus (Muthén \& Muthén, 1998-2012) in which each individual's mean-centered ages were used for the loadings of the latent slope. This model was fit with a random-effects structural equation model, which is necessary when using $\mathrm{T}$ scores. The estimates 
and CIs for all of these models can be found in Table 6. Figure 4 contains plots of mean-level change for the Big Six assessed by informant-reports.

Evaluating the Maturity Principle. We found partial support for the maturity principle: Agreeableness increased $\left(b=0.19, p=.036,95 \% \mathrm{CI}[0.01,0.37], d_{10}=0.11\right)$ and so did Conscientiousness $\left(b=0.38, p<.001,95 \%\right.$ CI $\left.[0.23,0.52], d_{10}=0.27\right)$. Decreases in Neuroticism were not significant in informant reports, but were in the same direction as the selfreport findings $\left(b=-0.09, p=.383,95 \% \mathrm{CI}[-0.29,0.11], d_{10}=-0.04\right)$. Likewise, increases in Honesty-Propriety were not significant, though they were in the same direction as self-reports $(b$ $=0.13, p=.154,95 \%$ CI $\left.[-0.05,0.30], d_{10}=0.07\right)$. These trends can be seen in Figure 4 , and estimates of the slopes and intercepts can be found in Table 6 .

Overall Extraversion seemed to increase over time $(b=0.28, p=.006,95 \%$ CI $[0.08$, 0.47], $d_{10}=0.14$ ), which is consistent with our findings from self-reports; we could not further evaluate changes in Social Dominance or Assertiveness, as we did not measure aspects with informant-reports. We also found small but significant decreases in average levels of Openness over time for informant-reports $\left(b=-0.18, p=.024,95 \%\right.$ CI $\left.[-0.33,-0.02], d_{10}=-0.13\right)$, which is consistent with our findings from self-reports.

Gender differences. Do we see gender differences in both average levels and rate of change for Neuroticism for informant-reports? We again found that women started off higher than men in Neuroticism $(b=-8.69, p<.001,95 \%$ CI $[-12.80,-4.58])$ and decreased faster than men (interaction $b=0.47, p=.022,95 \%$ CI [0.07, 0.87], $d_{10}=0.23$ ). As with self-reports, we found that women were significantly decreasing in Neuroticism across time $(b=-0.32, p=.003$, $95 \%$ CI $\left.[-0.54,-0.11], d_{10}=-0.16\right)$. Men, on the other hand, showed small, non-significant increases in Neuroticism $\left(b=0.15, p=.393,95 \%\right.$ CI $\left.[-0.19,0.48], d_{10}=0.07\right)$. Inspecting Figure 
Table 6. Informant-Report Growth Curve Model Parameters

\begin{tabular}{|c|c|c|c|c|c|}
\hline Trait & Parameter & Estimate & $d_{10}$ & $95 \% \mathrm{CI}$ & $p$ \\
\hline \multirow[t]{6}{*}{ Agreeableness } & Intercept & 69.49 & & {$[67.71,71.28]$} & $<.001$ \\
\hline & Gender & -0.69 & & {$[-4.24,2.86]$} & .704 \\
\hline & Linear Slope & 0.19 & 0.11 & {$[0.01,0.37]$} & .036 \\
\hline & Gender X Slope & -0.11 & -0.06 & {$[-0.45,0.23]$} & .518 \\
\hline & Intercept Variance & 296.69 & & {$[232.21,361.17]$} & $<.001$ \\
\hline & Slope Variance & 0.11 & & {$[-0.44,0.66]$} & .706 \\
\hline \multirow[t]{6}{*}{ Conscientiousness } & Intercept & 79.44 & & {$[77.80,81.08]$} & $<.001$ \\
\hline & Gender & -9.61 & & {$[-12.85,-6.38]$} & $<.001$ \\
\hline & Linear Slope & 0.38 & 0.27 & {$[0.23,0.52]$} & $<.001$ \\
\hline & Gender X Slope & 0.13 & 0.09 & {$[-0.15,0.41]$} & .375 \\
\hline & Intercept Variance & 199.07 & & {$[151.14,246.99]$} & $<.001$ \\
\hline & Slope Variance & 0.09 & & {$[-0.29,0.46]$} & .654 \\
\hline \multirow[t]{6}{*}{ Honesty-Propriety } & Intercept & 64.28 & & {$[62.31,66.24]$} & $<.001$ \\
\hline & Gender & -7.84 & & {$[-11.69,-3.99]$} & $<.001$ \\
\hline & Linear Slope & 0.13 & 0.07 & {$[-0.05,0.30]$} & .154 \\
\hline & Gender X Slope & -0.09 & -0.05 & {$[-0.44,0.26]$} & .606 \\
\hline & Intercept Variance & 306.68 & & {$[240.80,372.55]$} & $<.001$ \\
\hline & Slope Variance & 0.15 & & {$[-0.33,0.64]$} & .540 \\
\hline \multirow[t]{6}{*}{ Neuroticism } & Intercept & 40.67 & & {$[38.59,42.75]$} & $<.001$ \\
\hline & Gender & -8.69 & & {$[-12.80,-4.58]$} & $<.001$ \\
\hline & Linear Slope & -0.09 & -0.04 & {$[-0.29,0.11]$} & .383 \\
\hline & Gender X Slope & 0.47 & 0.23 & {$[0.07,0.87]$} & .022 \\
\hline & Intercept Variance & 413.12 & & {$[332.94,493.29]$} & $<.001$ \\
\hline & Slope Variance & 0.16 & & {$[-0.54,0.86]$} & .647 \\
\hline \multirow[t]{6}{*}{ Extraversion } & Intercept & 59.02 & & {$[56.92,61.12]$} & $<.001$ \\
\hline & Gender & -2.77 & & {$[-6.94,1.42]$} & .195 \\
\hline & Linear Slope & 0.28 & 0.14 & {$[0.08,0.47]$} & .006 \\
\hline & Gender X Slope & 0.01 & 0.01 & {$[-0.39,0.41]$} & .961 \\
\hline & Intercept Variance & 402.76 & & {$[332.33,473.18]$} & $<.001$ \\
\hline & Slope Variance & 0.15 & & {$[-0.34,0.64]$} & .540 \\
\hline \multirow[t]{6}{*}{ Openness } & Intercept & 72.03 & & {$[70.45,73.61]$} & $<.001$ \\
\hline & Gender & -0.75 & & {$[-3.89,2.40]$} & .641 \\
\hline & Linear Slope & -0.18 & -0.13 & {$[-0.33,-0.02]$} & .024 \\
\hline & Gender X Slope & -0.10 & -0.07 & {$[-0.40,0.21]$} & .533 \\
\hline & Intercept Variance & 195.98 & & {$[150.36,241.60]$} & $<.001$ \\
\hline & Slope Variance & 0.08 & & {$[-0.38,0.54]$} & .739 \\
\hline
\end{tabular}

Note. Gender was contrast coded $(\mathrm{Men}=.5$; Women $=-.5)$. Gender is the gender difference in the intercept. Gender X Slope is the gender difference in the slope. Estimate is the unstandardized parameter estimate. $d_{10}$ is the estimate divided by the standard deviation (square root of the intercept variance), multiplied by ten; it corresponds to the change in mean levels per decade relative to between-person standard deviation units. 

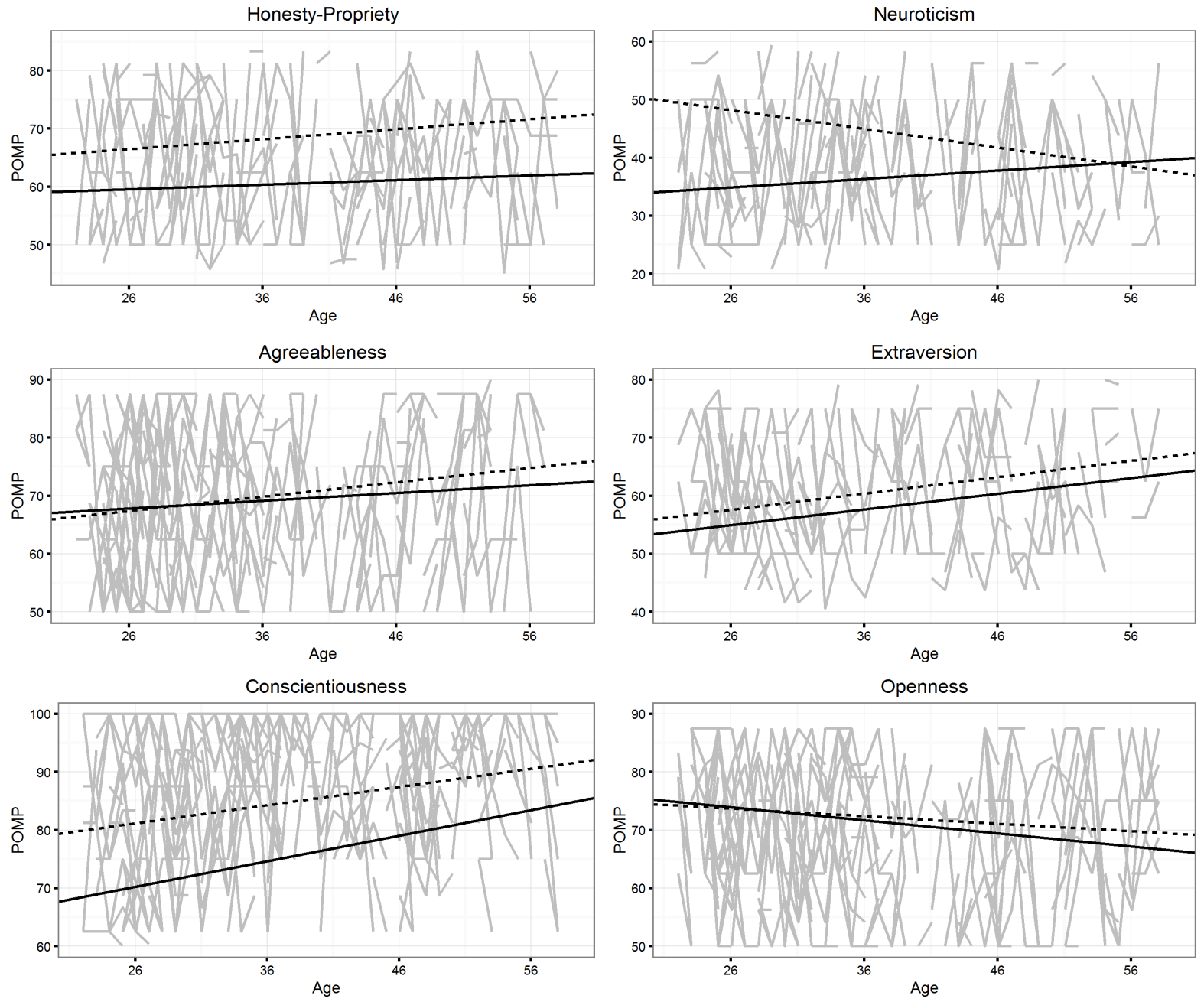

Gender
$\therefore$ Men
$\therefore$ Women

Figure 4. Mean-Level Change in Informant-Reports of Big Six. Fit lines were constructed based on results from Growth Curve Models. The grey lines in the background correspond to 300 individual participants' scores across the four time points. 
4 further suggests that men and women had comparable levels of Neuroticism in middleadulthood. Unlike our findings with self-reports, we found no gender differences in Agreeableness for informant reports. We did find gender differences in the intercepts of Conscientiousness and Honesty-Propriety ( $b$ 's and 95\% CIs $=-9.61[-12.85,-6.38]$ and $-7.84[-$ 11.69, -3.99] respectively; both $p$ 's $<.001$ ), which are consistent with findings from self-reports. In all, it seems that, women are typically higher than men in the domains of Neuroticism, Conscientiousness, and Honesty-Propriety, and that women show greater age-related declines in Neuroticism than men.

\section{Rank-Order Stability}

In the following analyses, we analyzed rank-order stability of self-reports of the Big Six and Big Five aspects, as well as informant-reports of the Big Six, at 1-, 2-, and 3-year retest intervals. We were specifically interested in examining age differences in stability and changes in stability as a function of the size of the retest interval. We performed these analyses using the Lavaan package in $\mathrm{R}$, retaining the strict measurement invariance models tested above, and modeling stability using latent variables representing a personality trait at each time point. Conducting stability analyses using latent variables has two related advantages: 1) stability estimates are corrected for attenuation due to measurement error, and 2) differences in stability across age groups cannot be attributed to differences in measurement quality across age groups.

Self-Report. For each trait we specified two stability models: a baseline model in which stability is constant across all of the decade-based age groups, and a model that allowed the age groups to have different stability estimates. The former is consistent with a working years plateau in which stability does not change over this study's age range of early- and middleadulthood (ages 18 to 58). The latter model is consistent with the unmodified cumulative 
continuity principle, which would predict that stability should be higher for older age groups, even within this study's range. Since participants provided four self-reports, each spaced one year apart, a simple correlational analysis would have three estimates of stability for a 1-year lag, two estimates of stability for a 2-year lag, and one estimate of stability for a 3-year lag. To pool multiple estimates and increase the precision of our estimates and power in model comparisons, the first model imposed equality constraints on estimates for equal lags (i.e., it pooled all of the 1-year-lag estimates with each other, and separately pooled 2-year-lag estimates with each other), and constrained estimates to be the same across age groups. The second model freed the equality constraints on age groups, allowing each age group to have a different estimate for each of the three lags.

Does the rank-ordering of individual differences become more stable over time as the cumulative continuity principle would suggest? Our data suggest that stability is relatively unchanging across the range of early- and middle-adulthood (ages 18-58). Table 7 displays the model fit indices for each of the two models, comparing one model where stability can differ between age groups (i.e., the cumulative continuity principle) to another model where stability cannot differ between age groups (i.e., the working-years-plateau model). Chi-Square difference tests were significant for the majority of the traits, against a null model of perfectly equal stability between age groups. However, AIC values are quite similar for the two models, and BIC values favor the working-years-plateau model (i.e., are smaller) in every case. Moreover, the RMSEA values are remarkably similar for each model (within .04 of each other) and CIs around these estimates generally overlap substantially, suggesting that they similarly fit the data.

The similarity in levels of stability across age groups can be seen by inspecting Figure 5a, which displays point-estimates and 95\% confidence intervals for stability estimates for each of 
Table 7. Model Fit Indices for Self-Report Stability Models

\begin{tabular}{|c|c|c|c|c|c|c|}
\hline Trait & Model & $d f$ & AIC & $\mathrm{BIC}$ & $\chi^{2}$ & RMSEA $[90 \% \mathrm{CI}]$ \\
\hline \multirow[t]{2}{*}{ Agreeableness } & $\mathrm{CC}$ & 333 & 12551.16 & 12679.53 & 401.32 & $.031[.018, .041]$ \\
\hline & WYP & 345 & 12552.75 & 12624.07 & $426.90 *$ & $.033[.021, .043]$ \\
\hline \multirow[t]{2}{*}{ Compassion } & $\mathrm{CC}$ & 333 & 10153.87 & 10282.24 & 482.15 & $.046[.036, .054]$ \\
\hline & WYP & 345 & 10160.50 & 10231.81 & $512.78 * *$ & $.048[.039, .056]$ \\
\hline \multirow[t]{2}{*}{ Politeness } & $\mathrm{CC}$ & 333 & 12676.91 & 12805.29 & 437.04 & $.038[.027, .048]$ \\
\hline & WYP & 345 & 12691.35 & 12762.67 & $475.49 * * *$ & $.042[.032, .051]$ \\
\hline \multirow[t]{2}{*}{ Conscientiousness } & $\mathrm{CC}$ & 333 & 12436.75 & 12565.12 & 428.62 & $.037[.025, .046]$ \\
\hline & WYP & 345 & 12444.10 & 12515.42 & $459.97 * *$ & $.039[.029, .049]$ \\
\hline \multirow[t]{2}{*}{ Industriousness } & $\mathrm{CC}$ & 333 & 12487.65 & 12616.03 & 418.44 & $.035[.023, .045]$ \\
\hline & WYP & 345 & 12485.06 & 12556.38 & $439.85^{*}$ & $.036[.025, .045]$ \\
\hline \multirow[t]{2}{*}{ Orderliness } & $\mathrm{CC}$ & 333 & 12893.96 & 13022.34 & 432.82 & $.037[.026, .047]$ \\
\hline & WYP & 345 & 12898.78 & 12970.10 & $461.64 * *$ & $.040[.030, .049]$ \\
\hline \multirow[t]{2}{*}{ Honesty-Propriety } & $\mathrm{CC}$ & 333 & 14218.57 & 14346.94 & 443.77 & $.039[.029, .049]$ \\
\hline & WYP & 345 & 14232.47 & 14303.78 & $481.67 * * *$ & $.043[.033, .052]$ \\
\hline \multirow[t]{2}{*}{ Neuroticism } & $\mathrm{CC}$ & 333 & 15067.54 & 15195.92 & 453.04 & $.041[.031, .050]$ \\
\hline & WYP & 345 & 15067.57 & 15138.89 & $477.07 *$ & $.042[.033, .051]$ \\
\hline \multirow[t]{2}{*}{ Withdrawal } & $\mathrm{CC}$ & 333 & 13584.32 & 13712.69 & 461.68 & $.042[.033, .051]$ \\
\hline & WYP & 345 & 13578.06 & 13649.38 & 479.42 & $.043[.033, .051]$ \\
\hline \multirow[t]{2}{*}{ Volatility } & $\mathrm{CC}$ & 333 & 13808.52 & 13936.89 & 398.70 & $.030[.017, .041]$ \\
\hline & WYP & 345 & 13816.81 & 13888.13 & $430.99 * *$ & $.034[.022, .044]$ \\
\hline \multirow[t]{2}{*}{ Extraversion } & $\mathrm{CC}$ & 333 & 13552.17 & 13680.55 & 374.59 & $.024[.000, .036]$ \\
\hline & WYP & 345 & 13539.48 & 13610.80 & 385.89 & $.024[.000, .035]$ \\
\hline \multirow[t]{2}{*}{ Assertiveness } & $\mathrm{CC}$ & 333 & 11969.54 & 12097.91 & 454.88 & $.041[.031, .050]$ \\
\hline & WYP & 345 & 11978.59 & 12049.91 & $487.94 * *$ & $.044[.035, .053]$ \\
\hline \multirow[t]{2}{*}{ Enthusiasm } & $\mathrm{CC}$ & 333 & 12479.33 & 12607.71 & 401.65 & $.031[.018, .042]$ \\
\hline & WYP & 345 & 12483.11 & 12554.43 & $429.42 * *$ & $.034[.022, .044]$ \\
\hline \multirow[t]{2}{*}{ Openness } & $\mathrm{CC}$ & 333 & 11306.05 & 11434.42 & 505.96 & $.049[.040, .058]$ \\
\hline & WYP & 345 & 11316.48 & 11387.80 & $540.39 * *$ & $.051[.043, .060]$ \\
\hline \multirow[t]{2}{*}{ Intellect } & $\mathrm{CC}$ & 333 & 11171.19 & 11299.56 & 516.11 & $.051[.042, .059]$ \\
\hline & WYP & 345 & 11177.04 & 11248.36 & $545.97 * *$ & $.052[.044, .060]$ \\
\hline \multirow[t]{2}{*}{ Openness } & $\mathrm{CC}$ & 333 & 11796.07 & 11924.44 & 422.48 & $.035[.024, .045]$ \\
\hline & WYP & 345 & 11813.56 & 11884.88 & $463.98 * * *$ & $.040[.030, .049]$ \\
\hline
\end{tabular}

Note. $*=\mathrm{p}<.05 ; * *=\mathrm{p}<.01 ; * * *=\mathrm{p}<.001$. CC is an abbreviation of Cumulative Continuity, and is the model where age groups can have different stability estimates. WYP is an abbreviation of Working Years Plateau, and is the model where age groups have equal stability estimates. $p$ values refer to ChiSquare difference test between the models. Aspects from the BFAS are indented. 


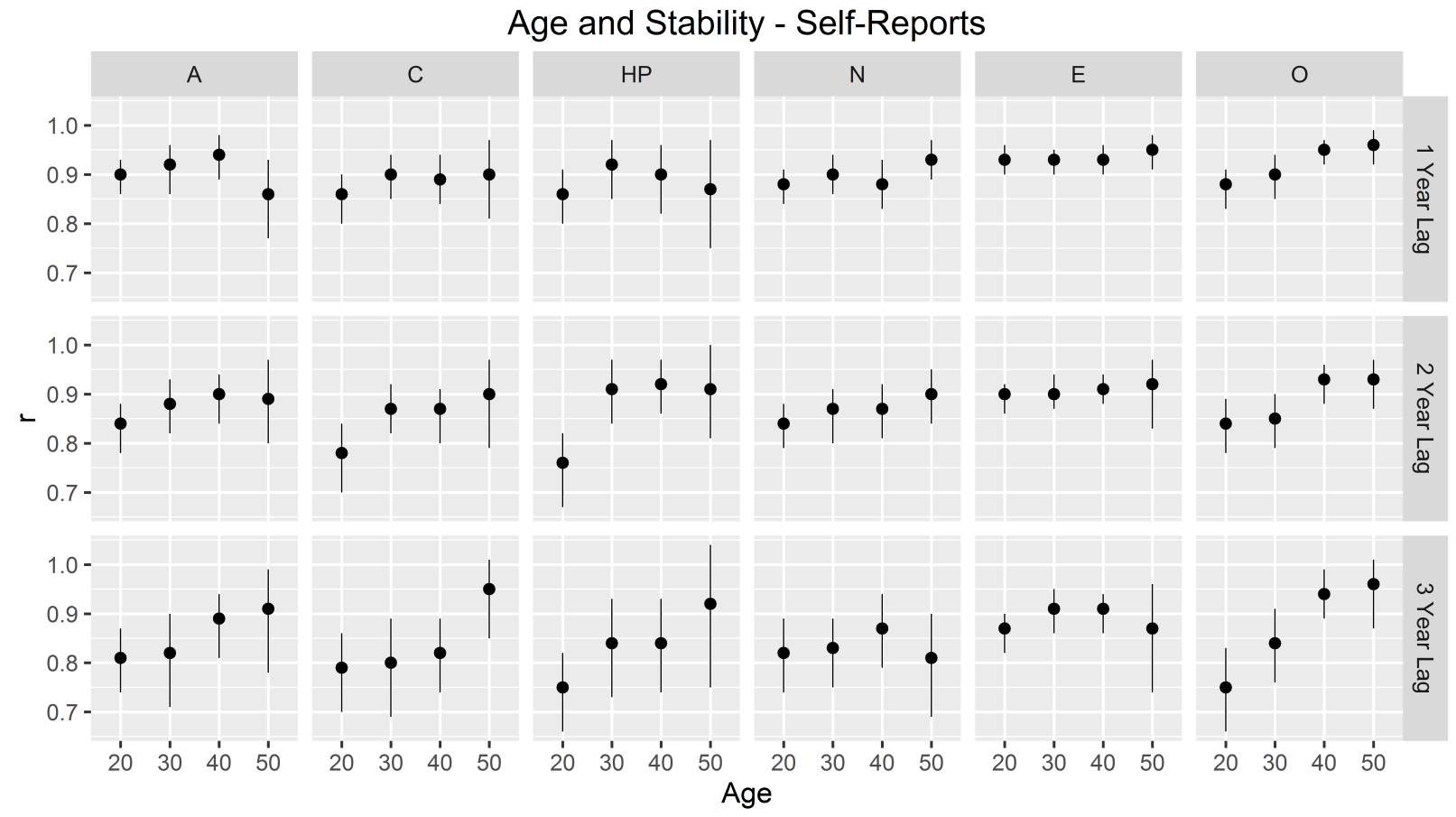

Figure 5a. Age and Stability for Self-Reported Big Six. Points represent point estimates for stability; bars represent 95\% confidence intervals obtained via bootstrapping (500 resamples).

Age and Stability - Informant-Reports

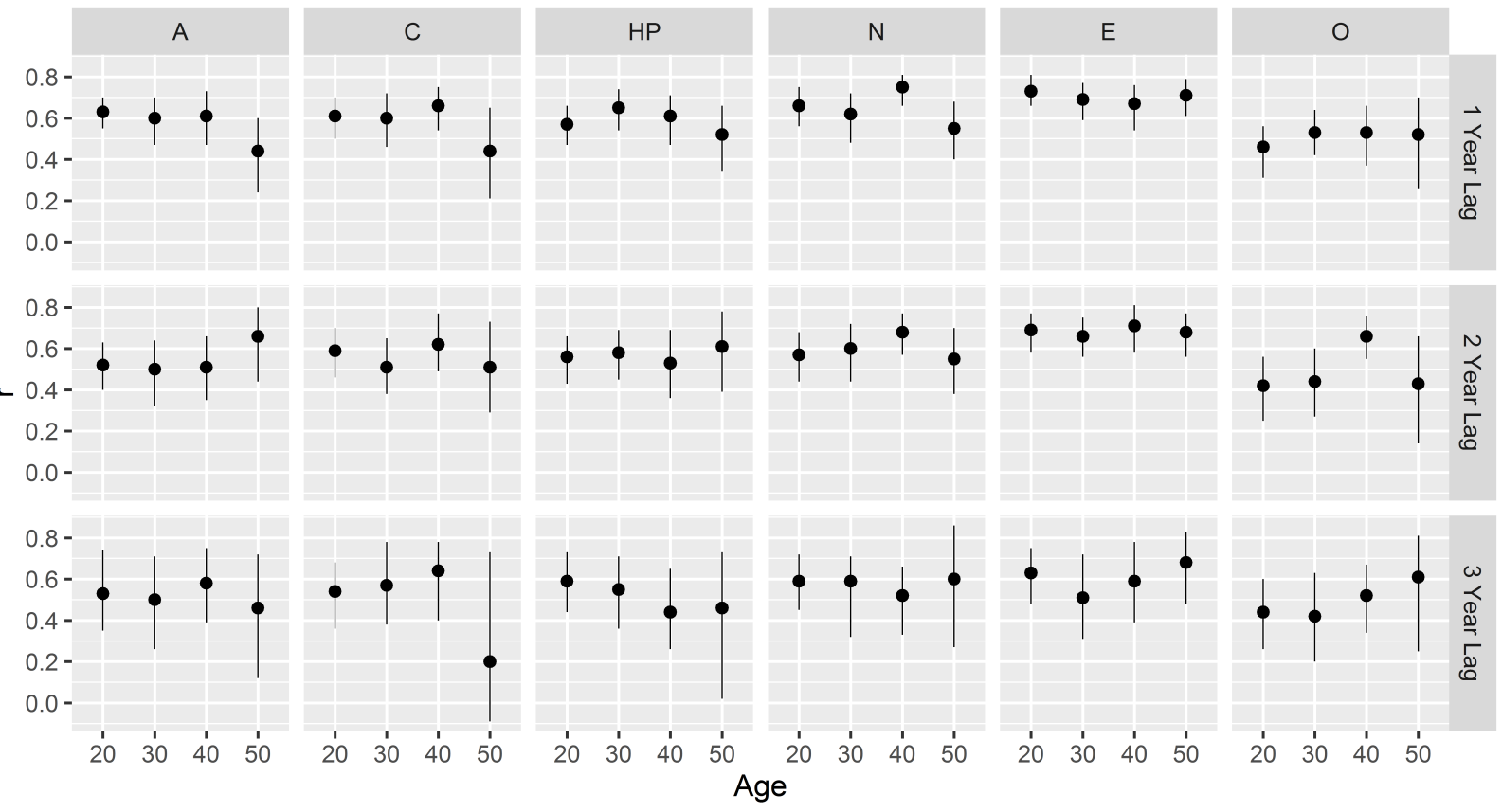

Figure 5b. Age and Stability for Informant-Reported Big Six. Points represent point estimates for stability; bars represent 95\% confidence intervals obtained via bootstrapping (500 resamples). 
the Big Six and for each lag. We utilized bootstrapping to calculate CIs, and used 500 resamples. Perhaps one of the most striking things about these estimates is how large they are compared to meta-analytic findings (Roberts \& DelVecchio, 2000): point estimates range from a low of .75 for three year time-lags to a high of .96 for one-year lags. Importantly, the estimates here are obtained via correlations between latent variables, and so they correct for attenuation due to measurement error. A second thing to note is that stability estimates for different age groups are within each other's confidence intervals, with the exception of two-year lags of HonestyPropriety and three-year lags of Openness. A third thing to note is that the stability estimates show small declines as the time-lag increases; the average stability estimate across domains and age groups are .91,.88, and .86 for 1-, 2-, and 3-year lags respectively. This pattern is upheld in Honesty-Propriety as well, with stability estimates of .89, .88, and .84 for 1-, 2-, and 3-year lags respectively. Analyses at the aspect level led to similar conclusions, showing negligible differences in rank-order stability by age group (see Table 7 for fit statistics for the aspect models and Supplement Figure S2 for the estimates and CIs). Thus, our data suggest that after correcting for measurement error: 1) stability estimates are much higher than typically found, 2) age differences are generally small or non-existent, 3) there are small decreases in stability of the Big Six as a function of the size of the retest interval.

Informant-Reports. Are there any notable differences in stability estimates based informant reports? We were not able to use latent variable models for informant-reports, since they completed only two items, and there were often only one or two informants per target. So, comparing the magnitude of estimates across methods is an apples-and-oranges comparison. Instead, we can see if the pattern is upheld. That is, do we find evidence in favor of a working years plateau in stability? 
In short, we do. The Chi-Square difference tests were not significant with the exception of Conscientiousness, suggesting that the working years plateau model fits the data as well as the unmodified cumulative continuity model for 5 of the Big Six. Moreover, in all cases, both AIC and BIC are lower (i.e., better) for all of the Big Six, suggesting that slight sacrifice in fit for the working years plateau models are justified by their gains in parsimony (see Table 8). We also find comparable RMSEA values (and highly overlapping CIs) for each model. Finally, inspecting Figure 5b reveals two things of note. First, age groups' estimates are within each other's confidence bands, as we saw with self-reports, further suggesting little to no change in stability across this range of adulthood. Second, we see small declines in stability as a function of the retest interval; the average stability estimate across domains and age groups are $.60, .57$, and .53 for 1-, 2-, and 3-year lags respectively. This pattern is again seen in Honesty-Propriety as well, with stability estimates of $.58, .57, .51$ for 1-, 2-, and 3-year lags respectively. The informant data thus suggest that: 1) changes in stability with age are small to non-existent, and 2) stability estimates of the Big Six show small declines as a function of the size of the retest interval.

\section{Discussion}

Returning to the question posed at the outset of this paper: how much and in what ways does personality change over the course of adulthood? In a large cross-sequential longitudinal study, we found evidence of mean-level change consistent with the maturity principle (Roberts et al., 2008): people tended to increase in Agreeableness, Conscientiousness, and HonestyPropriety, and decrease in Neuroticism with age. Moreover, the evidence for the maturity principle is bolstered by the fact that findings mostly converged across methods. We also found that the rank-ordering of personality characteristics was highly stable across adulthood, indeed, 
Table 8. Model Fit Indices for Informant-Report Stability Models

\begin{tabular}{lllcccc}
\hline \multicolumn{1}{c}{ Trait } & Model & $d f$ & AIC & BIC & $\chi^{2}$ & RMSEA [90\% CI] \\
\hline Agreeableness & CC & 24 & 13080.33 & 13220.54 & 26.48 & $.026[.000, .074]$ \\
& WYP & 36 & 13072.49 & 13160.13 & 42.64 & $.035[.000, .071]$ \\
Conscientiousness & CC & 24 & 12535.33 & 12675.55 & 49.60 & $.085[.051, .118]$ \\
& WYP & 36 & 12542.23 & 12629.87 & $80.50^{* *}$ & $.091[.065, .118]$ \\
Honesty-Propriety & CC & 24 & 13246.20 & 13386.42 & 35.47 & $.057[.000, .094]$ \\
& WYP & 36 & 13232.79 & 13320.43 & 46.05 & $.043[.000, .077]$ \\
Neuroticism & CC & 24 & 13413.72 & 13553.94 & 31.41 & $.046[.000, .086]$ \\
\multirow{5}{*}{ Extraversion } & WYP & 36 & 13405.39 & 13493.02 & 47.08 & $.046[.000, .079]$ \\
& CC & 24 & 13077.63 & 13217.85 & 33.60 & $.052[.000, .090]$ \\
Openness & WYP & 36 & 13062.05 & 13149.68 & 42.02 & $.034[.000, .070]$ \\
& CC & 24 & 12803.62 & 12943.83 & 24.40 & $.011[.000, .068]$ \\
& WYP & 36 & 12794.32 & 12881.95 & 39.10 & $.024[.000, .065]$ \\
\hline
\end{tabular}

Note. ${ }^{*}=\mathrm{p}<.05 ; * *=\mathrm{p}<.01 ; * * *=\mathrm{p}<.001$

more stable than previous research would have suggested. However, we found little to no

evidence in favor of the unmodified cumulative continuity principle, where stability steadily increases. Instead we found evidence in favor of a working years plateau, in which the stability of personality is relatively unchanging during the bulk of early- and middle-adulthood. We elaborate below on the implications of these findings for both the above theories, and how these findings fit more generally into the field's understanding of continuity and change in personality characteristics.

\section{Mean-Level Change \& Maturity}

The maturity principle holds that people tend to increase in those characteristics necessary to succeed in adulthood, and reflects a socialization perspective on maturity (Caspi et al., 2004; Helson \& Wink, 1987; Roberts et al., 2008). The characteristics of interest to the maturity principle have typically included the socialization-related domains of Agreeableness, Conscientiousness, and Emotional Stability/Neuroticism. While this theory has been highly influential within the field of personality development, it had never faced a theoretically novel 
test, as it was induced from the patterns of change seen in the existing personality taxonomy (i.e., the Big Five; Caspi et al., 2004; Roberts et al., 2006, 2008). The advent of the Big Six provided an opportunity of testing a novel prediction made by the maturity principle, that HonestyPropriety would show normative increases.

The maturity principle predicts normative increases in Honesty-Propriety, due to this domain's position in hierarchical representations of personality within Social Self-Regulation (Saucier \& Srivastava, 2015), its morally-charged content, and its relevance to concepts of communion or getting along (Bakan, 1966; Hogan, 1983). Moreover, socialization, which is central to the maturity principle, is thought to involve the internalization of prescriptive social and moral norms (Helson \& Wink, 1987), and increases in Honesty-Propriety should accompany such internalization, as its content primarily concern norm-following and rule-abiding (Saucier, 2009; Ashton \& Lee, 2007). That is, the increases in Honesty-Propriety that we found likely reflects the successful internalization of social and moral norms, as the maturity principle would predict.

Patterns of normative development do not seem to depend heavily on who you ask. That is, informant-reports generally supported the maturity principle as well; according to TRIM, this evidence is consistent with changes in personality traits rather than only identity or only reputation more distinctly (McAbee \& Connelly, 2016). Ambiguities in this converging evidence were found in Neuroticism and Honesty-Propriety. In the informant reports, although the main effect of age on Neuroticism was not significant, Neuroticism did show the same gender-by-age interaction found in self-reports and the gender-specific effects (women decreased, men stayed relatively unchanging), and so was mostly consistent with self-report findings. With respect to Honesty-Propriety, mean-level increases in this domain were significant in the self-reports but 
not in the informant-reports. Because of differences in measurement between self- and informant-reports, we did not conduct a direct statistical test to see if slopes from the two data sources were significantly different from one another. But the differences in statistical significance tests could be due to the lower sensitivity of the informant tests, which used a smaller number of items and a smaller subsample. Indeed, the CI for the informant-report spans from -0.05 to 0.30 POMP units per year, and thus spans from virtually no change, to increases on par with our findings from self-reported Honesty-Propriety.

An alternative possibility is that there could be an underlying substantive difference in mean-level change between self-reports and informant reports. Mean-level changes in personality assessed through informant reports are often weaker than self-reports but directionally similar (Jackson et al., 2009; McCrae et al., 2004). According to the TRIM model, self-reports uniquely pick up on identity and informant reports uniquely pick up on reputation; it could be that identity changes more than reputation. In light of the ambiguities of both measurement and interpretation, we are inclined to conclude that Honesty-Propriety increases with age, but with the caveat that further investigation of informant reports might complicate this interpretation in the future.

Outside of the normative change anticipated and explained by the maturity principle, we also found significant and consistent change in the domains of Extraversion and Openness in both self- and informant-reports. Specifically, we found mean-level increases in Extraversion and decreases in Openness with age. Normative decreases in Openness have been found within this age range previously (Srivastava et al., 2003; Soto et al., 2011; Specht et al., 2011), but normative increases in Extraversion have not typically been found. Given that this effect is small and at odds with previous work, we do not draw strong or clear conclusions from it. Our sample 
differs from previous ones in various ways, such as in its recruitment and sampling approach; future research may shed more light on whether that or other considerations explain the difference between our findings and previous work.

Gender differences. Differences between men and women in normative personality development have been less consistently found, with some studies finding them (Srivastava et al., 2003; Soto et al., 2011) and others not finding them (Roberts et al., 2006; Specht et al., 2011). We found gender differences in both the intercept and slope in Neuroticism in a similar pattern to previous studies that have reported gender differences, such that women started off at a higher level of Neuroticism in early adulthood but then decreased more rapidly than men. Indeed, while the evidence consistently showed women decreasing in Neuroticism, men showed small non-significant declines or inclines depending upon the method. The gender gap in Neuroticism at earlier ages may imply that women face relatively greater adversity, perhaps stemming from the presence of gender stereotypes, at earlier ages than men (Srivastava et al., 2003; Soto et al., 2011).

The aspects of Neuroticism paint a similar picture. Women started off adulthood higher in Withdrawal than men, but declined at faster rates than men. For Volatility, there was some evidence for a cross-over wherein women showed mean-level decreases and men show small mean-level increases. Men's increases in Volatility were not significant, and the CI ranged from a small negative slope to a medium-to-large positive slope, and so the evidence is equivocal. Moreover, previous research on personality development in adulthood has little to offer in clearing this up, as other studies either have not used aspects or facets of Neuroticism (Roberts et al., 2006; Srivastava et al., 2003; Specht et al., 2011), or used facets with highly different content (Soto et al., 2011). Moreover, we only have self-reports of aspects, which limited us from 
checking for multi-method convergence. Thus, firm conclusions should await further research on gender differences in normative trajectories of the aspects and facets of Neuroticism.

Outside of Neuroticism and its aspects, we found gender differences in the intercepts of several domains and aspects, suggesting that men and women have different average levels of these characteristics. Assertiveness showed an interesting pattern of results, where women started off lower on this characteristic, but seemed to increase while men's levels seemed to stay relatively flat or decrease slightly. However, it is worth noting that neither simple slope was significant. Assertiveness is highly analogous to Social Dominance, which has shown mixed evidence of normative change. Our findings suggest that while normative increases in social dominance do not seem to characterize the overall population as Roberts and colleagues (2006) found, it may characterize the adult development of women specifically. Although the available studies have not found gender differences in the normative development of Extraversion's facets (Roberts et al., 2006; Soto et al., 2011), Wink and Helson (1993) found that women, but not men, increased in self-confidence, which is conceptually similar to assertiveness. However, Helson, Jones, and Kwan (2002) did not find significant gender differences in trajectories of dominance, a characteristic analogous to assertiveness, within a sample with both men and women. They did find that a sample with only women (i.e., the Mills sample) increased more rapidly in dominance than the men in their mixed sample (see Figure 3a in Helson et al., 2002). Given the equivocal nature of our own and previous evidence, firm conclusions about gender differences in normative trajectories of Assertiveness should await further research.

\section{Stability \& Cumulative Continuity}

Personality researchers have generally drawn five conclusions about the rank-order stability of individual differences, noting that rank-order stability is: 1) similar across different 
personality characteristics, 2) similar across assessment methods, 3) smaller as the lag or testretest interval increases, 4) moderate in size throughout adulthood, and 5) greater with increasing age (Caspi et al., 2004; Fraley \& Roberts, 2005; Roberts \& DelVecchio, 2000; Roberts et al., 2008). Our results are consistent with the first three statements: we found similar levels of stability across the Big Six, similar patterns of stability across self- and informant-reports, and decreases in stability moving from 1-, to 2-, to 3-year lags. However, our results are somewhat at odds with the final two above points: we found strikingly high levels of stability even amongst the youngest age group (18-29), and we found little evidence of increasing stability with age. We consider these two differences in turn.

High estimated stability. One of the most striking aspects of our findings are the high levels of stability we found, which are notably higher than previous findings. Point estimates averaged across age groups and Big Six domains were .91, .88, and .86 for 1-, 2-, and 3-year lags respectively. For comparison, the highest average stability estimate from Roberts and DelVecchio's meta-analysis was .75 for individuals between 50 and 59 .

One important difference between this study and some previous work is our use of latent variable models to correct for attenuation due to measurement error, which could partly explain the higher levels of stability that we found in the present study. Our estimates were also higher than Lucas and Donnellan (2011) found also using latent-variable models, albeit in a different cultural context (Germany) and a reduced item set items (three items per Big Five factor).

High levels of latent stability suggest that there is limited room for a person's position in the rank-ordering of personality characteristics to change within a three-year span. Moreover, given that levels of stability have been interpreted as evidence of the relative strength of dynamic and constant processes in development (Fraley \& Roberts, 2005), the present results could be 
interpreted as evidence of a greater role of developmental constants in personality than previously thought. Indeed, this is further bolstered by the limited degree to which stability declined across greater retest intervals, as well as the lack of age-related differences in stability.

However, this conclusion requires addressing an important limitation of the present study: the relatively short developmental window of three years, which is about half the length of the average lag in Roberts and DelVecchio's (2000) study. Although the developmental window of this study is on par with some other studies of personality stability (Specht et al., 2011; Watson \& Humrichouse, 2006), it does represent an important limitation of this study, as it is possible that stability decreases substantially moving beyond lags of 3 years. An important next step for research on stability is to address this by assessing stability across longer lags, while utilizing modeling techniques that allow correcting attenuation due to measurement error as was done presently.

It is worth further noting that high levels of stability can be achieved not solely through constants within the person (such as stable genetic influences), but also constants within the person's environment. Indeed, behavioral genetic techniques have found that genes and environments both contribute to phenotypic stability, and that the relative contributions of each is about equal by the time the individual reaches middle age (Briley \& Tucker-Drob, 2015). The strikingly high levels of stability cannot thus be taken by themselves as evidence solely in favor of strict biological accounts of personality stability (e.g., Five Factor Theory; McCrae \& Costa, 2008). The high levels of stability seen here could be the result of some mixture of stable genetic influences, stable environmental influences, environmental transactions where people select and transform environments in ways that support their existing traits, and identity processes (Buss, 1987; McAdams, 2001; Roberts et al., 2008). 
No increase in rank-order stability. It is these transactional and identity processes that the cumulative continuity principle holds accumulate over the life course, ultimately leading to increasing stability with age (Roberts et al., 2008). What are the implications of our finding that rank-order stability did not increase in early and middle adulthood? The youngest age group in the present study, people in their 20's, were already near the ceiling of stability ( $r$ averaged across traits and lags was .84 for the 20's group), leaving little room for stability to increase. While these results are at odds with an unmodified cumulative continuity principle, they seem to be consistent with previous studies showing very little change during the bulk of early- and middle-adulthood (Roberts \& DelVecchio, 2000; Watson \& Humrichouse, 2006). It thus seems that stability reaches a working years plateau, where it remains relatively unchanging during the bulk of adulthood, and may increase as people enter the workforce (in their early 20's) and prepare to leave the workforce (sometime after their mid to late 50's). It is possible that individuals reach an equilibrium of sorts at this point in development, where the presence and strength of developmental constants, transactional processes, and stochastic processes are relatively similar across this span of adulthood.

Another possibility is that stability reaches a permanent plateau during young adulthood, which has suggested previously by Terraciano and colleagues $(2006,2010)$. This permanent plateau has been explained via Five Factor Theory (McCrae \& Costa, 2008), which holds that biological maturation slows or stops at this point in the lifespan, ultimately leading to a leveling off of stability and change in personality characteristics. Unfortunately, it is not possible to test this model against the working-years-plateau model in the present dataset, as both predict no change in stability during the period of life covered in this study (18-58). The cumulative continuity principle suggests that stability will continue to increase later, though Lucas and 
Donnellan's (2011) analyses extended later into adulthood and found a decrease in stability in old age. Future research using a larger age range should test these models against one another by further investigating what happens to stability after the plateau found in early- to middleadulthood.

Again, it is worth noting the relatively short developmental window of the present study, and its implication for evaluating the cumulative continuity principle with or without the working years plateau. Specifically, it is possible that increases in stability associated with age become apparent only at longer test-retest intervals than were studied here. Drawing upon Fraley and Roberts (2005) model, this would suggest that different age groups have different relative levels of dynamic and constant processes, which would ultimately lead to different asymptotic values of stability. Or, to put it simply, it is possible that younger individuals show larger decrements of stability as the retest interval increases relative to older individuals, which would be consistent with a model wherein older people have a greater ratio of constant to dynamic processes. This would be evidenced by a lag-by-age-group interaction predicting stability. Future research should address this possibility in a design with a larger range of lags.

In all, our evidence about rank-order stability suggests that: a) stability is similar across different personality traits, b) patterns of stability are similar across methods of assessment, c) stability decreases slightly as the lag between assessments grows, d) stability is very high throughout early- and middle-adulthood, and e) stability is relatively unchanging throughout early- and middle-adulthood. Although there may still be cumulative continuity in personality, it seems that stability has a working years plateau.

\section{Conclusion}


We utilized a cross-sequential, multi-method design to investigate personality change and stability of the Big Six. We found evidence consistent with the maturity principle: people increased in Agreeableness, Conscientiousness, Emotional Stability (particularly women), and Honesty-Propriety. After correcting for measurement error, we found strikingly high levels of stability in all traits (including H-P). We found little to no evidence for the unmodified cumulative continuity principle, and instead found evidence in favor of a working-years-plateau modification to this theory. In all, it seems that the rank-ordering of personality traits is highly stable during adulthood, which is accompanied by normative increases in personality traits that help the individual maintain stable relationships of respect and trust with others. 


\section{References}

Adler, N., \& Stewart, J. (2007). The MacArthur scale of subjective social status. MacArthur Research Network on SES \& Health. Retrieved from http://www. macses. ucsf. edu/Research/Psychosocial/subjective.php.

Ashton, M. C., \& Lee, K. (2007). Empirical, theoretical, and practical advantages of the HEXACO model of personality structure. Personality and Social Psychology Review, 11, 150-66. http://doi.org/10.1177/1088868306294907

Ashton, M. C., Lee, K., Perugini, M., Szarota, P., de Vries, R. E., Di Blas, L., .. De Raad, B. (2004). A six-factor structure of personality-descriptive adjectives: solutions from psycholexical studies in seven languages. Journal of Personality and Social Psychology, 86, 356-366. http://doi.org/10.1037/0022-3514.86.2.356

Bakan, D. (1966). The duality of human existence: Isolation and communion is western man. Boston, MA: Beacon Press.

Bates, D., Maechler, M., Bolker, B., \& Walker, S. (2015). Fitting linear mixed-effects models Using lme4. Journal of Statistical Software, 67, 1-48. doi:10.18637/jss.v067.i01.

Bleidorn, W., Klimstra, T. a., Denissen, J. J. a., Rentfrow, P. J., Potter, J., \& Gosling, S. D. (2013). Personality maturation around the world: A cross-cultural examination of socialinvestment theory. Psychological Science, 24, 2530-2540. http://doi.org/10.1177/0956797613498396

Briley, D. a., \& Tucker-Drob, E. M. (2014). Genetic and environmental continuity in personality development: A meta-analysis. Psychological Bulletin, 140, 1303-1331. http://doi.org/10.1037/a0037091 
Buss, D. M. (1987). Selection, evocation, and manipulation. Journal of Personality and Social Psychology, 53, 1214-1221. http://doi.org/10.1037//0022-3514.53.6.1214

Cohen, P., Cohen, J., Aiken, L. S., \& West, S. G. (1999). The problem of units and the circumstance for POMP. Multivariate Behavioral Research, 34, 315-346.

DeYoung, C. G. (2006). Higher-order factors of the Big Five in a multi-informant sample. Journal of Personality and Social Psychology, 91, 1138-1151.

DeYoung, C. G., Quilty, L. C., \& Peterson, J. B. (2007). Between facets and domains: 10 aspects of the big five. Journal of Personality and Social Psychology, 93, 880-896.

Digman, J. M. (1997). Higher-order factors of the big five. Journal of Personality and Social Psychology, 73, 1246-1256. http://doi.org/10.1037//0022-3514.73.6.1246

Duncan, S. C., \& Duncan, T. E. (1996). A multivariate latent growth curve analysis of adolescent substance abuse. Structural Equation Modeling, 3, 323-347.

Fiske, S. T., Cuddy, A. J. C., \& Glick, P. (2007). Universal dimensions of social cognition: warmth and competence. Trends in Cognitive Sciences, 11, 77-83. http://doi.org/10.1016/j.tics.2006.11.005

Fraley, R. C., \& Roberts, B. W. (2005). Patterns of continuity: A dynamic model for conceptualizing the stability of individual differences in psychological constructs across the life course. Psychological Review, 112, 60-74. http://doi.org/10.1037/0033295X.112.1.60

Goodwin, G. P., Piazza, J., \& Rozin, P. (2014). Moral character predominates in person perception and evaluation. Journal of Personality and Social Psychology, 106, 148-68. http://doi.org/10.1037/a0034726 
Gregorich, S. E. (2006). Do self-report instruments allow meaningful comparisons across diverse population groups? Testing measurement invariance using the confirmatory factor analysis framework. Medical Care, 44 (11 Suppl 3), S78-S94. doi:

10.1097/01.mlr.0000245454.12228.8f

Hogan, R., \& Roberts, B. W. (2004). A Socioanalytic model of maturity. Journal of Career Assessment, 12, 207-217. http://doi.org/10.1177/1069072703255882

John, O. P., Naumann, L. P., \& Soto, C. J. (2008). Paradigm shift to the integrative big five trait taxonomy. In O. P. John, R. W. Robins, \& L. A. Pervin (Eds.), Handbook of Personality: Theory and Research (pp. 114-158). New York, NY: Guilford. http://doi.org/10.1016/S0191-8869(97)81000-8

John, O. P., \& Robins, R. W. (1994). Accuracy and bias in self-perception: individual differences in self-enhancement and the role of narcissism. Journal of Personality and Social Psychology, 66, 206-219. http://doi.org/10.1037/0022-3514.66.1.206

Kammrath, L. K., Mendoza-Denton, R., \& Mischel, W. (2005). Incorporating if...then...personality signatures in person perception: beyond the person-situation dichotomy. Journal of personality and social psychology, 88, 605-618. doi:10.1037/00223514.88.4.605

Kenny, D. A. (1994). Interpersonal perception: A social relations analysis. New York, NY: Guilford Press.

Little, T. D., Cunningham, W. A., Shahar, G., \& Widaman, K. F. (2002). To parcel or not to parcel: exploring the question, weighing the merits. Structural Equation Modeling: A Multidisciplinary Journal, 9, 151-173. http://doi.org/10.1207/S15328007SEM0902_1 
McAbee, S. T., \& Connelly, B. S. (2016). A multi-rater framework for studying personality: The trait-reputation-identity model. Psychological Review, 1-23. http://doi.org/10.1037/rev0000035

McAdams, D. P. (2001). The psychology of life stories. Review of General Psychology, 5, 100122. http://doi.org/10.1037/1089-2680.5.2.100

Muthén, L. K. \& Muthén, B. O. (1998-2012). Mplus user's guide. Seventh Edition. Los Angeles, CA: Muthén \& Muthén.

R Core Team (2016). R: A language and environment for statistical computing. R Foundation for Statistical Computing, Vienna, Austria. URL https://www.R-project.org/.

Rammstedt, B., \& John, O. P. (2007). Measuring personality in one minute or less: A 10-item short version of the big five inventory in English and German. Journal of Research in Personality, 41, 203-212. http://doi.org/10.1016/j.jrp.2006.02.001

Reeder, G. D. (2009). Mindreading: judgments about intentionality and motives in dispositional inference. Psychological inquiry, 20, 1-18. doi:10.1080/10478400802615744

Revelle, W. (2016) psych: Procedures for Personality and Psychological Research, Northwestern University, Evanston, Illinois, USA, http://CRAN.R-project.org/package=psych Version = 1.6.4.

Roberts, B. W., \& DelVecchio, W. F. (2000). The rank-order consistency of personality traits from childhood to old age: A quantitative review of longitudinal studies. Psychological Bulletin, 1, 3-25. http://doi.org/10.1037/0033-2909.126.1.3

Roberts, B. W., Walton, K. E., \& Viechtbauer, W. (2006). Patterns of mean-level change in personality traits across the life course: a meta-analysis of longitudinal studies. Psychological Bulletin, 132, 1-25. http://doi.org/10.1037/0033-2909.132.1.1 
Roberts, B. W., Wood, D., \& Caspi, A. (2008). Development of personality traits in adulthood. In O. P. John, R. W. Robins, \& L. A. Pervin (Eds.), Handbook of Personality: Theory and Research (pp. 375-398). New York, NY: Guilford.

Rosseel, Y. (2012). lavaan: An r package for structural equation modeling. Journal of Statistical Software, 48, 1-36. URL http://www.jstatsoft.org/v48/i02/.

Saucier, G. (2009). Recurrent personality dimensions in inclusive lexical studies: indications for a big six structure. Journal of Personality, 77, 1577-1614. http://doi.org/10.1111/j.14676494.2009.00593.x

Saucier, G. \& Srivastava, S. (2015). What makes a good structural model of personality? Evaluating the big five and alternatives. In M. Mikulincer, P. R. Shaver, M. L. Cooper \& R. J. Larsen (Eds.), Handbook of personality and social psychology. Vol. 3: Personality processes and individual differences (pp. 283-305). Washington, DC: APA Books.

Saucier, G., Thalmayer, A. G., Payne, D. L., Carlson, R., Sanogo, L., Ole-Kotikash, L., ... Zhou, X. (2014). A Basic Bivariate Structure of Personality Attributes Evident Across Nine Languages. Journal of Personality, 82, 1-14. http://doi.org/10.1111/jopy.12028

Schaie, K. W. (1965). A general model for the study of developmental problems. Psychological Bulletin, 64, 92-107.

Schmitt, N. (1996). Uses and abuses of coefficient alpha. Psychological assessment, 8, 350-353. http://dx.doi.org/10.1037/1040-3590.8.4.350

Smillie, L. D., Deyoung, C. G., \& Hall, P. J. (2015). Clarifying the relation between extraversion and positive affect. Journal of Personality, 83, 564-574. http://doi.org/10.1111/jopy.12138 
Soto, C. J., John, O. P., Gosling, S. D., \& Potter, J. (2011). Age differences in personality traits from 10 to 65: Big five domains and facets in a large cross-sectional sample. Journal of Personality and Social Psychology, 100, 330-348. http://doi.org/10.1037/a0021717

Specht, J., Egloff, B., \& Schmukle, S. C. (2011). Stability and change of personality across the life course: The impact of age and major life events on mean-level and rank-order stability of the big five. Journal of Personality and Social Psychology, 101, 862-882. http://doi.org/10.1037/a0024950

Srivastava, S., John, O. P., Gosling, S. D., \& Potter, J. (2003). Development of personality in early and middle adulthood: Set like plaster or persistent change? Journal of Personality and Social Psychology, 84, 1041-1053. http://doi.org/10.1037/0022-3514.84.5.1041

Terracciano, A., Costa Jr, P. T., \& Mccrae, R. R. (2006). Personality plasticity after age 30. Personality and Social Psychology Bulletin, 32, 999-1009. http://doi.org/10.1177/0146167206288599.

Terracciano, A., McCrae, R. R., \& Costa, P. T. (2010). Intra-individual change in personality stability and age. Journal of Research in Personality, 44, 31-37. http://doi.org/10.1016/j.jrp.2009.09.006

Thalmayer, A. G., Saucier, G., \& Eigenhuis, A. (2011). Comparative validity of brief to mediumlength big five and big six personality questionnaires. Psychological Assessment, 23, 995-1009. http://doi.org/10.1037/a0024165

Wojciszke, B., Abele, A., \& Baryla, W. (2009). Two dimensions of interpersonal attitudes: Liking depends on communion, respect depends on agency. European Journal of Social Psychology, 990, 973-990. http://doi.org/10.1002/ejsp 


\section{Footnotes}

${ }^{1}$ In text, we present analyses for Agreeableness as measured by the Big Five Inventory (John, Naumann, \& Soto, 2008), and as conceptualized in the Big Five. This was done to make our results more comparable to previous work, and to allow comparing the findings of Agreeableness with the lower order aspects found in the Big Five Aspects Scale (DeYoung et al., 2007). All relevant self-report analyses were also conducted with Agreeableness as conceptualized in Big Six models, and these are presented in the supplement.

${ }^{2} \mathrm{We}$ did conduct post-hoc exploratory analyses on provisional Honesty-Propriety aspects. These analyses are presented in the supplement. 


\section{Supplement}

\section{Further Description of Measurement Models}

In order to test for measurement invariance, we specified two models for each of the Big Six domains and Big Five aspects. The first model imposed strict invariance across waves within age groups, but allowed different age groups to have different measurement models. To use H-P as an example, we specified four latent variables, which corresponded to scores on H-P at each time point. These latent variables each had three indicators, one for each of the H-P parcels. The first parcel was used as the reference indicator for each of the 4 latent variables. We set parcel loadings to be equal across time, such that each parcel had the same loading at each time point (e.g., Parcel 2's loading was the same at Time 1, Time 2, etc.). We set parcel intercepts to be equal across time. We set the error variances for each parcel to be equal across time (e.g., Parcel 2's error variance was the same at Time 1, Time 2, etc.). We allowed parcels to have correlated uniqueness across time (e.g., Parcel 2's error variance at Time 1 was allowed to correlate with Parcel 2's error variance at Time 2, etc.), and these were constrained to be equal across time (e.g., the correlation between Parcel 2's error variance at Time 1 and Time 2 was constrained to be equal to the correlation between Parcel 2's error variance at Time 2 and Time 3, etc.). The same was done for the remaining Big Six personality domains and Big Five aspects. In practical terms, the first model assumes that there is no difference in measurement properties across time, but it allows for differences in measurement properties attributable to age group.

The second model imposed measurement invariance across age groups. The second model looked identical to the first model with one exception: the model was constrained to be identical across age groups (e.g., the loading of Parcel 2 was the same across Time Points and across age groups). This was done for each of the Big Six personality domains and Big Five 
aspects. In practical terms, the second model adds the assumption that there is no difference in measurement properties attributable to age group.

\section{Six-Factor Model Agreeableness}

As mentioned in the main text, Agreeableness changes to center on patience and eventemperedness in the Big Six, rather than its core content of warmth and compassion found in the Big Five. We focused on Big-Five Agreeableness in the main text to more directly compare our findings to previous work, and for cohesion between the broader domain/factor level analyses and the analyses with the BFAS; the aspects for Agreeableness, Compassion and Politeness, were developed with Big Five Agreeableness in mind, and Big Six Agreeableness is likely to have a different lower-order structure. However, for completeness, we have run the same analyses that were presented in the main text on Six-Factor Agreeableness. We present each below in turn.

We measured Big Six Agreeableness using five items from the 48QB6 (Thalmayer et al., 2011) and three additional items. All eight items, their corrected item-total correlations at each time point, and Cronbach's alpha from each time point are presented in Supplemental Table S1b.

Measurement Invariance. We tested for measurement invariance of Big Six Agreeableness in precisely the same way as we did for the other domains and aspects investigated in this study. We created three parcels from the eight items using the domain representative approach (Little et al., 2002). Two models were specified for Big Six Agreeableness. The first imposed strict measurement invariance across time points (i.e., strict longitudinal invariance) and no measurement invariance across age groups (i.e., no crosssectional invariance). The second added constraints to impose strict measurement invariance across age groups (i.e., strict cross-sectional invariance). 
We found strong evidence consistent with strict measurement invariance for Big Six Agreeableness (see Supplemental Table S3). First, the Chi-Square difference test was not significant, which suggests that we are unable to reject the null hypothesis of perfect measurement invariance. This is particularly impressive given the large sample size $(N=858)$ and fairly large difference in parsimony (a difference of 33 parameter estimates). Further evidence of measurement invariances comes from the parsimony-adjusted fit measures, AIC and BIC. AIC and BIC are both lower (i.e., better) for the strict measurement invariance model, suggesting that the increased fit produced by allowing each age group to have their own measurement model does not justify the additional 33 parameters. Finally, the RMSEA values are nearly identical (.025 and .027 for the non-invariance and strict-invariance models respectively), and the CIs around the RMSEA estimates overlap considerably. Finally, dividing the Chi-Square values by their associated degrees of freedom result in almost identical values for the non-invariance (1.14) and strict-invariance (1.16) models. Thus, the evidence from different fit measures all converge in suggesting that Big Six Agreeableness shows strict measurement invariance across different age groups.

Mean-Level Change. As with the analyses presented in text, we investigated mean-level change in Big Six Agreeableness by fitting a curve-of-factors model (Duncan \& Duncan, 1996), in which growth parameters (a latent slope and latent intercept) load onto latent variables rather than observed variables, retaining the measurement models fit previously. The loadings for the latent slope were set to each individuals" grand-mean centered age using “T scores" in Mplus version 7.31 (Muthén \& Muthén, 1998-2012). The model was fit with a random-effects Structural Equation Modeling, which is necessary when using T scores. We modeled gender differences in both the slope and intercept by regressing each on a contrast code for gender (Men 
$=.5$; Women $=-.5$ ). The estimates from this model with Big Six Agreeableness are presented in Supplemental Table S4, and Supplemental Figure S2 displays mean-level change of Big Six Agreeableness.

We found mean-level increases in Big Six Agreeableness $(b=.22, p<.001,95 \%$ CI [.15, $\left..36], d_{10}=0.14\right)$, suggesting that people tend to become more even-tempered, patient, and forgiving with age. Turning to gender differences, it appears that gender is unrelated to the intercept $(b=.17, p=.897,95 \%$ CI $[-2.41,2.76])$. This suggests that men and women have comparable levels of Big Six Agreeableness at our sample's average age of 36. Gender is related to differences in the slope $\left(b=-.27, p=.031,95 \%\right.$ CI $\left.[-.51,-.03], d_{10}=-0.17\right)$; simple slope analyses suggest that men are not significantly changing in this domain $(b=.09, p=.384,95 \%$ CI $\left.[-.11, .29], d_{10}=0.06\right)$ whereas women are significantly increasing in this domain $(b=.36, p$ $<.001,95 \%$ CI $\left.[.22, .50], d_{10}=0.22\right)$. This pattern can be seen clearly in Supplemental Figure S2, where men's regression line is nearly flat and women's regression line is quite steep.

Rank-Order Stability. We modeled rank-order stability in Big Six Agreeableness by estimating the covariance among latent Big Six Agreeableness across time points. As with the analyses presented in text, estimates from the same length lag were pooled; we had three estimates of rank-order stability at a one-year lag, two estimates of rank-order stability at a twoyear lag, and one estimate of rank-order stability at a three-year lag. Similarly to the other Big Six domains and Big Five Aspects, we tested the cumulative continuity principle with Big Six Agreeableness by specifying two models: one in which stability estimates could differ between age groups and one in which all age groups had the same stability estimates. The cumulative continuity principle would predict that the former would fit the data better, and further predict that rank-order stability is relatively higher among the older age groups. 
Supplemental Table S4 depicts the fit indices for these two models and stability estimates with 95\% CIs around them for each age group are displayed in Supplemental Figure S3. A similar picture emerged with Big Six Agreeableness as with the remaining Big Six domains and Big Five Aspects presented in text. Specifically, the evidence suggests that the two models fit the data similarly. The chi-square difference test was significant, which provides weak evidence in favor of the model in which rank-order stability estimates can differ between age groups (i.e., the model consistent with the cumulative continuity principle). However, AIC, a parsimony adjusted fit index, was highly similar for the two models as can be seen in Supplemental Table S4. BIC was substantially lower (i.e., better) for the model that constrained the rank-order stability estimates to be the same across age groups. This suggests that allowing age groups to have different rank-order stability estimates does not produce a large enough increase in fit to justify the sacrifice in parsimony. The RMSEA values are highly similar, and the CIs around them overlap substantially. Finally, inspecting Supplemental Figure S3 further demonstrates the similarity of stability estimates across the four decades of age examined in this study. Taken together, these results are consistent with the analyses of the remaining Big Six and Big Five Aspects, and suggest that a working years plateau is a justifiable refinement to the cumulative continuity principle.

Big Six Agreeableness also shows decreases in stability at larger test-retest intervals, as anticipated by Fraley and Roberts (2005). Pooled across age groups, stability estimates for one-, two-, and three-year lags are $.88, .85$, and .79 respectively. This pattern suggests that Big Six Agreeableness, like the remaining Big Six and Big Five Aspects, reflects a mixture of developmental constants, dynamic, and stochastic processes. Finally, it is worth noting that these 
estimates are quite a bit higher than would be anticipated based on previous work, which is consistent with the results presented in the main text.

\section{Honesty-Propriety Aspects}

The lower-order structure of Honesty-Propriety has yet to be explored systematically. However, we did conduct exploratory analyses separating the eight-item Honesty-Propriety scale administered to participants into two aspects: Honesty and Propriety. We separated items into these two exploratory aspects on conceptual grounds: the items concerning honesty and other core moral content (e.g., "Uses other for my own ends") comprise the Honesty aspect, and the items concerning following social rules and norms ("Sticks to the rules") comprise the Propriety aspect. Supplementary Table S1b contains the eight items, and the items are marked for which exploratory aspect in which they were included. Because the Honesty and Propriety subscales consisted of five and three items respectively, we did not test measurement invariance and rankorder stability and mean-level change are modeled on observed (rather than latent) variables.

Mean-Level Change. We assessed mean-level change in the two aspects of HonestyPropriety using a random-effects latent growth curve model in Mplus, in which a latent intercept and latent slope are fitted to the average scale scores at each time-point. The loadings of the latent slope were set to each individual's grand-mean-centered age using “Tscores” in Mplus. To assess possible gender differences, we regressed the latent slope and intercept on a contrast code for gender $($ men $=.5$; women $=-.5)$.

Parameter estimates from the models are displayed in Supplemental Table S6, and the results are plotted in Supplemental Figure S5. Turning first to the Honesty aspect, we found a significant linear slope, suggesting that people increase in Honesty as they age. Likewise, Propriety's slope was significant, suggesting that people become more proper with age, though it 
had a descriptively flatter slope than Honesty. Thus, each exploratory aspect of HonestyPropriety shows a pattern consistent with the broader domain.

Turning to gender differences, we found gender differences in the intercept of both aspects, but no gender differences in the slope. This suggests that women are higher in both Honesty and Propriety at the sample's mean age of 36. This can be seen clearly in Supplemental Figure S5, in which the regression lines for men and women are nearly parallel, and women have a regression line higher than men.

Rank-Order Stability. We modeled rank-order stability in Honesty-Propriety's aspects by estimating the covariance among average scores on each across time points. As with other rank-order stability analyses presented in the supplement and main text, estimates from the same sized lag were pooled; we had three estimates of rank-order stability at a one-year lag, two estimates of rank-order stability at a two-year lag, and one estimate of rank-order stability at a three-year lag. We tested the cumulative continuity principle against the working years plateau with these aspects by specifying two models: one in which stability estimates could differ between age groups and one in which all age groups had the same stability estimates. The cumulative continuity principle would predict that the former would better fit the data, and further predict that stability is higher among the older age groups.

Supplemental Table S7 contains the model fit indices for each of these models for both the Honesty aspect and the Propriety aspect. As can be seen in the table, the evidence mostly favored the working years plateau. The Chi-square difference test was significant for Propriety, which rejects the null of no loss of fit by constraining age groups to have the same stability estimates. However, the parsimony-adjusted fit indices, AIC and BIC, are lower for the working years plateau model for both aspects, suggesting that the greater fit produced by allowing each 
age group to have a different stability estimate is not worth the decrease in parsimony. Finally, across both aspects, RMSEA values are highly similar for the two models, and the CIs around the RMSEA estimates overlap considerably. This suggests that the two models fit the data similarly, and that little fit is gained from allowing age groups to have different stability estimates. Supplemental Figure S6 shows the stability estimates and CIs around them for each estimated separately for each age group; the small differences in stability across age groups can be seen in that figure. Taken together, the evidence suggests that there are little to no differences in the stability of the aspects of Honesty-Propriety, providing more evidence consistent with the working-years-plateau model.

Finally, as expected based on work by Fraley \& Roberts (2005), we found that stability estimates were lower for larger test-retest intervals for the aspects of Honesty-Propriety. Pooled across age groups, rank-order stability for the Honesty aspect was .72, .68, and .67 for one-, two, and three-year lags respectively. Likewise, rank-order stability for the Propriety aspect was .70, .67 , and .64 for one-, two-, and three-year lags respectively. Thus, as we saw with the broader domain, rank-order stability of the aspects of Honesty-Propriety declines as the test-retest interval or lag increases, suggesting that each characteristic is affected by a combination of constant, dynamic, and stochastic processes.

\section{Exploring Discrepancy in Mean-Level Change of H-P in Self- and Informant-Reports}

In the main text, we note that mean-level changes in Honesty-Propriety for informantreports were not significant, which was discrepant with the findings from self-report. While we cannot formally test many of the possible reasons for this discrepancy in the present data, we were able to test the extent to which this was due to the particular items used in the informantreport measure of H-P. That is, it is possible that mean-level change for $\mathrm{H}-\mathrm{P}$ as measured by 
informant-reports failed to reach significance because the items selected happen to correspond to aspects of $\mathrm{H}-\mathrm{P}$ that change less than aspects not selected. To the extent that this is the case, we would expect to see those items show similarly less evidence of change in self-reports. To examine this, we conducted exploratory analyses using latent growth curve models on self- and informant-reports of each of the two single items used in informant-reports; this resulted in four models, one for each item and each source.

The informant-report consisted of two items from the larger H-P subscale: "Sticks to the rules" and "Take risks that could cause trouble for me" (reverse-scored). For these analyses, each item was POMP scored, and a latent slope and intercept loaded on the POMP scored item from each time point. As with other mean-level change analyses reported, the loadings of the slope were each individuals' grand mean-centered age at each time point. We modeled gender differences by regressing the latent slope and intercept on a contrast code for gender $($ men $=.5$; Women $=-.5)$.

Parameter estimates from the self- and informant-report models are presented in Supplemental Tables S8 and S9 respectively. We found that self-reports of the item "Sticks to the rules" increased significantly over time, mirroring findings from the overall domain. Selfreports of the item "Takes risks that could cause trouble for me" were not increasing significantly over time. Turning to informant-reports, neither item showed evidence of increasing over time. Thus, it appears that the discrepancy in mean-level change in H-P in self- and informant-reports may have been influenced by content coverage, given that only one of the two items showed mean-level change in self-reports. However, since neither reached significance in informant-reports, it is unlikely that this discrepancy is due entirely to the particular content covered by informant-report items. 
Supplemental Table S1a. Item total correlations for H-P items

\begin{tabular}{|c|c|c|c|c|}
\hline \multirow[t]{2}{*}{ Item } & \multicolumn{4}{|c|}{ Corrected Item Total Correlation } \\
\hline & Time 1 & Time 2 & Time 3 & Time 4 \\
\hline Takes risks that could cause trouble for me. ${ }^{P}$ & .44 & .46 & .51 & .47 \\
\hline Uses others for my own ends. ${ }^{\mathrm{H}}$ & .62 & .63 & .63 & .66 \\
\hline Would never take things that aren't mine. ${ }^{\mathrm{H}}$ & .44 & .53 & .42 & .40 \\
\hline Sticks to the rules. ${ }^{\mathrm{P}}$ & .49 & .43 & .44 & .50 \\
\hline Is not good at deceiving other people. ${ }^{\mathrm{H}}$ & .44 & .34 & .34 & .38 \\
\hline Uses flattery to get ahead. ${ }^{\mathrm{H}}$ & .39 & .33 & .41 & .35 \\
\hline Misrepresents the facts. ${ }^{\mathrm{H}}$ & .50 & .54 & .51 & .54 \\
\hline Has bad manners. ${ }^{\mathrm{P}}$ & .33 & .36 & .38 & .33 \\
\hline
\end{tabular}

Note. Item total correlations were obtained using the Psych package in R (Revelle, in prep.). Items below the dotted line are not from the 48QB6. The superscripted letter corresponds to which of the exploratory facets/aspects the item belongs to $\left({ }^{\mathrm{H}}=\right.$ Honesty; ${ }^{\mathrm{P}}=$ Propriety $)$.

Supplemental Table S1b. Item total correlations for Agreeableness-6 items

\begin{tabular}{|c|c|c|c|c|}
\hline \multirow{2}{*}{ Item } & \multicolumn{4}{|c|}{ Corrected Item Total Correlation } \\
\hline & Time 1 & Time 2 & Time 3 & Time 4 \\
\hline Is usually a patient person. & .45 & .50 & .47 & .56 \\
\hline Is inclined to forgive others. & .62 & .60 & .65 & .66 \\
\hline Gets angry easily. & .59 & .59 & .58 & .60 \\
\hline Becomes frustrated and angry with people when they don't live up to my expectations. & .55 & .52 & .52 & .46 \\
\hline Get back at people who insult me. & .54 & .54 & .48 & .54 \\
\hline Trusts what people say. & .50 & .47 & .54 & .52 \\
\hline Holds grudges. & .69 & .73 & .73 & .69 \\
\hline Distrusts people. & .59 & .62 & .64 & .64 \\
\hline Cronbach's Alpha & .79 & .79 & .80 & .80 \\
\hline
\end{tabular}

Note. Item total correlations were obtained using the Psych package in R (Revelle, in prep.). Items below the dotted line are not from the 48QB6. 
Supplemental Table S2. Cronbach's Alpha for Each Subscale at Each Measurement Occasion

\begin{tabular}{ccccc}
\hline \multicolumn{1}{c}{ Trait } & Time 1 & Time 2 & Time 3 & Time 4 \\
\hline Agreeableness & 0.81 & 0.80 & 0.82 & 0.82 \\
Compassion & 0.89 & 0.89 & 0.89 & 0.89 \\
Politeness & 0.78 & 0.78 & 0.78 & 0.77 \\
Conscientiousness & 0.83 & 0.82 & 0.83 & 0.83 \\
Industriousness & 0.86 & 0.85 & 0.85 & 0.85 \\
Orderliness & 0.78 & 0.79 & 0.78 & 0.80 \\
Honesty-Propriety & 0.68 & 0.69 & 0.68 & 0.68 \\
Neuroticism & 0.86 & 0.86 & 0.86 & 0.88 \\
Volatility & 0.91 & 0.90 & 0.90 & 0.91 \\
Withdrawal & 0.88 & 0.87 & 0.88 & 0.89 \\
Extraversion & 0.88 & 0.87 & 0.87 & 0.88 \\
Assertiveness & 0.89 & 0.88 & 0.88 & 0.88 \\
Enthusiasm & 0.86 & 0.86 & 0.86 & 0.87 \\
Openness & 0.81 & 0.81 & 0.82 & 0.82 \\
Intellect & 0.84 & 0.82 & 0.85 & 0.84 \\
Openness & 0.80 & 0.81 & 0.81 & 0.81 \\
\hline
\end{tabular}

Note. Aspects from the BFAS are indented. For clarity, Big Six Agreeableness is omitted from this table, but Cronbach's alpha is presented for it in Supplemental Table S1b. 
Supplemental Table S3. Model Fit Indices for Measurement Invariance Test of Six-Factor Agreeableness

\begin{tabular}{clccccc}
\hline Trait & Invariance & $d f$ & AIC & BIC & $\chi^{2}$ & RMSEA [90\% CI] \\
\hline Agreeableness Six & None & 276 & 14989.42 & 15388.81 & 313.61 & $.025[.000, .038]$ \\
& Strict Factorial & 309 & 14968.91 & 15211.39 & 359.10 & $.027[.010, .039]$ \\
\hline
\end{tabular}

Note. $*=\mathrm{p}<.05 ; * *=\mathrm{p}<.01 ; * * * \mathrm{p}<.001 . p$ values refer to Chi-Square difference test between the two measurement models. 
Supplemental Table S4. Self-Report Curve of Factors Model Parameters for Six-Factor Agreeableness

\begin{tabular}{clcccr}
\hline Trait & \multicolumn{1}{c}{ Parameter } & Estimate & $d_{10}$ & $95 \%$ CI & $p$ \\
\hline \multirow{2}{*}{ Agreeableness Six } & Gender & 0.17 & & {$[-2.41,2.76]$} & .897 \\
& Linear Slope & 0.22 & 0.14 & {$[0.15,0.36]$} & $<.001$ \\
& Gender X Slope & -0.27 & -0.17 & {$[-0.51,-0.03]$} & .031 \\
& Intercept Variance & 264.00 & & {$[217.44,312.55]$} & $<.001$ \\
& Slope Variance & 0.09 & & {$[-0.20,0.38]$} & .536 \\
\hline
\end{tabular}

Note. Gender was contrast coded $(\mathrm{Men}=.5$; Women $=-.5)$. The Latent Intercept is not displayed in the above table because it was constrained to be equal to zero in all of the above models; this constraint is commonly used in Curve of Factors Models. Gender is the gender difference in the intercept. Gender X Slope is the gender difference in the slope. Estimate is the unstandardized parameter estimate. $d_{10}$ is the estimate divided by the standard deviation (square root of the intercept variance), multiplied by ten; it corresponds to the change in mean levels per decade relative to between-person standard deviation units. 
Supplemental Table S5. Model Fit Indices for Six-Factor Agreeableness Stability Models

\begin{tabular}{|c|c|c|c|c|c|c|}
\hline Trait & Model & $d f$ & AIC & $\mathrm{BIC}$ & $\chi^{2}$ & RMSEA $[90 \% \mathrm{CI}]$ \\
\hline Agreeableness Six & $\mathrm{CC}$ & 333 & 14951.47 & 15388.81 & 389.66 & $.028[.013, .039]$ \\
\hline & WYP & 345 & 14953.82 & 15025.14 & $416.01 * *$ & $.031[.018, .041]$ \\
\hline
\end{tabular}

Note. $*=\mathrm{p}<.05 ; * *=\mathrm{p}<.01 ; * * *=\mathrm{p}<.001 . \mathrm{CC}$ is an abbreviation of Cumulative Continuity, and is the model where age groups can have different stability estimates. WYP is an abbreviation of Working Years Plateau, and is the model where age groups have equal stability estimates. $p$ values refer to ChiSquare difference test between the two models. 
Table S6. Self-Report Latent Growth Curve Model Parameters for Post-Hoc Honesty-Propriety Aspects

\begin{tabular}{clcccc}
\hline \multicolumn{1}{c}{ Trait } & \multicolumn{1}{c}{ Parameter } & Estimate & $d_{10}$ & $95 \%$ CI & \multicolumn{1}{c}{$p$} \\
\hline Honesty & Intercept & 70.17 & & {$[69.01,71.33]$} & $<.001$ \\
& Gender & -7.23 & & {$[-9.55,-4.91]$} & $<.001$ \\
& Linear Slope & 0.37 & 0.26 & {$[.27, .48]$} & $<.001$ \\
& Gender X Slope & 0.03 & 0.02 & {$[-.18, .25]$} & .766 \\
& Intercept Variance & 202.82 & & {$[170.86,235.31]$} & $<.001$ \\
Propriety & Slope Variance & 0.09 & & {$[-0.14,0.32]$} & .454 \\
& Intercept & 70.02 & & {$[68.76,71.29]$} & $<.001$ \\
& Gender X Intercept & -7.70 & & {$[-10.22,-5.18]$} & $<.001$ \\
& Linear Slope & 0.19 & 0.13 & {$[.08, .31]$} & .001 \\
& Gender X Slope & 0.14 & 0.09 & {$[-.09, .37]$} & .243 \\
& Intercept Variance & 223.74 & & {$[188.65,258.84]$} & $<.001$ \\
& Slope Variance & 0.13 & & {$[-0.11,0.36]$} & .282 \\
\hline
\end{tabular}

Note. Gender was contrast coded $(\mathrm{Men}=.5$; Women $=-.5)$. Gender is the gender difference in the intercept. Gender X Slope is the gender difference in the slope. Estimate is the unstandardized parameter estimate. $d_{10}$ is the estimate divided by the standard deviation (square root of the intercept variance), multiplied by ten; it corresponds to the change in mean levels per decade relative to between-person standard deviation units. 
Supplemental Table S7. Model Fit Indices for Post-Hoc Honesty-Propriety Aspects Stability Models

\begin{tabular}{llccccc}
\hline \multicolumn{1}{c}{ Trait } & \multicolumn{1}{c}{ Model } & $d f$ & AIC & BIC & $\chi^{2}$ & RMSEA [90\% CI] \\
\hline Honesty & CC & 24 & 4259.09 & 4411.13 & 24.57 & $.011[.000, .057]$ \\
& WYP & 36 & 4250.85 & 4345.87 & 40.33 & $.024[.000, .056]$ \\
Propriety & CC & 24 & 4748.66 & 4900.70 & 36.45 & $.049[.002 .080]$ \\
& WYP & 36 & 4746.92 & 4841.94 & $58.70 *$ & $.054[.027, .079]$ \\
\hline
\end{tabular}


Table S8. Self-Report Latent Growth Curve Model Parameters for Single H-P Items used in InformantReports

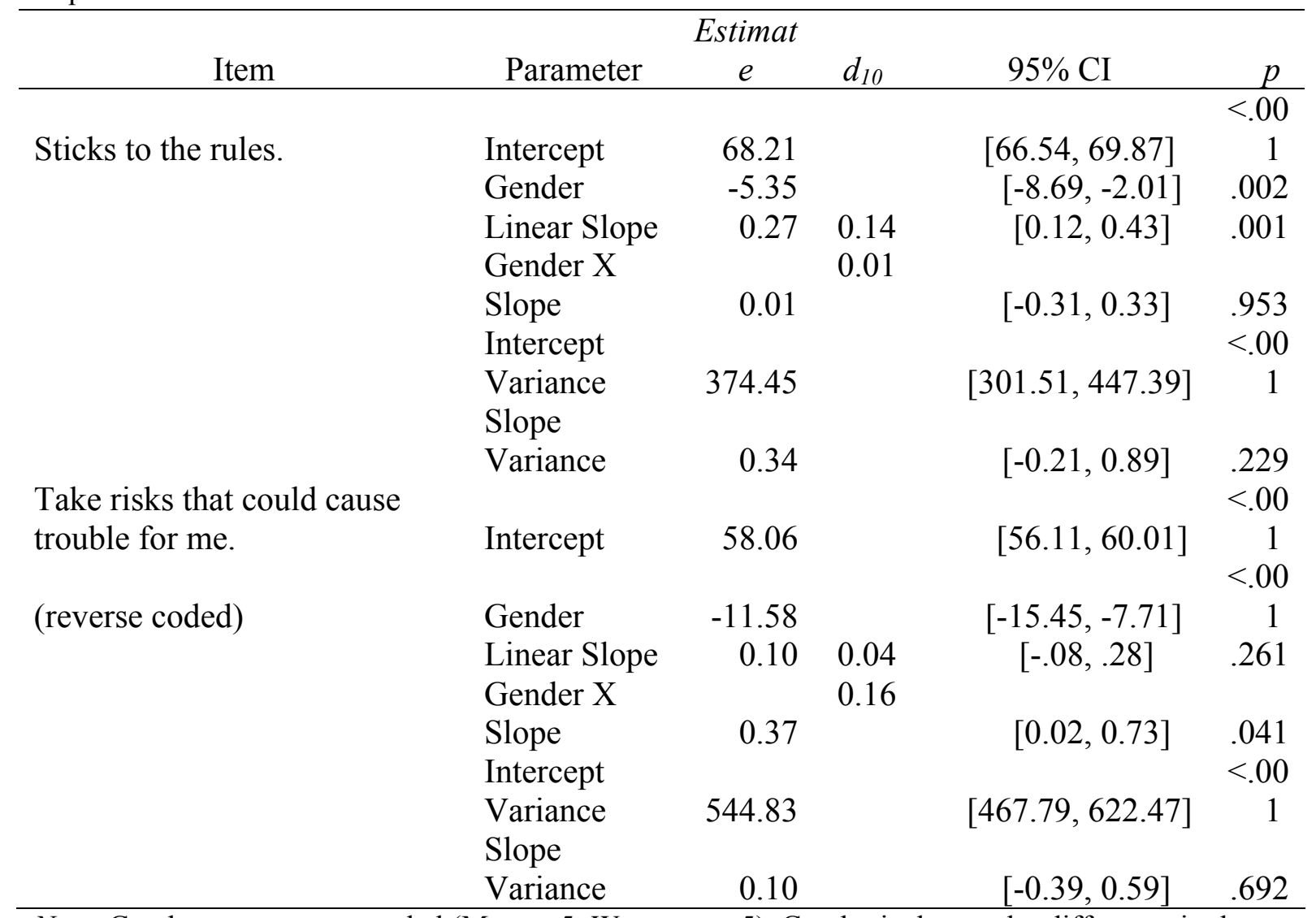

Note. Gender was contrast coded (Men $=.5$; Women $=-.5$ ). Gender is the gender difference in the intercept. Gender X Slope is the gender difference in the slope. Estimate is the unstandardized parameter estimate. $d_{10}$ is the estimate divided by the standard deviation (square root of the intercept variance), multiplied by ten; it corresponds to the change in mean levels per decade relative to between-person standard deviation units. 
Table S9. Informant-Report Latent Growth Curve Model Parameters for Each H-P Item Separately

\begin{tabular}{llrrrr}
\hline \multicolumn{1}{c}{ Item } & \multicolumn{1}{c}{ Parameter } & Estimate & $d_{10}$ & \multicolumn{1}{c}{$95 \%$ CI } & $p$ \\
\hline Sticks to the rules. & Intercept & 67.63 & & {$[64.58,70.67]$} & $<.001$ \\
& Gender & -0.36 & & {$[-1.40,0.67]$} & .493 \\
& Linear Slope & 0.64 & 0.31 & {$[-0.38,1.65]$} & .218 \\
& Gender X Slope & -0.01 & -0.01 & {$[-0.03,0.01]$} & .267 \\
& Intercept Variance & 334.19 & {$[251.71,416.66]$} & $<.001$ \\
& Slope Variance & 0.18 & {$[-0.51,0.87]$} & .603 \\
Take risks that could cause & & & & \\
trouble for me. & Intercept & 65.78 & {$[62.28,69.27]$} & $<.001$ \\
(reverse coded). & Gender & -0.42 & {$[-1.53,0.69]$} & .457 \\
& Linear Slope & 0.56 & 0.29 & {$[-0.52,1.65]$} & .310 \\
& Gender X Slope & -0.02 & -0.01 & {$[-0.04,0.01]$} & .120 \\
& Intercept Variance & 372.19 & {$[279.26,465.12]$} & $<.001$ \\
& Slope Variance & 0.37 & {$[-0.22,0.97]$} & .221 \\
\hline
\end{tabular}

Note. Gender was contrast coded (Men $=.5$; Women $=-.5$ ). Gender is the gender difference in the intercept. Gender X Slope is the gender difference in the slope. Estimate is the unstandardized parameter estimate. $d_{10}$ is the estimate divided by the standard deviation (square root of the intercept variance), multiplied by ten; it corresponds to the change in mean levels per decade relative to between-person standard deviation units. 

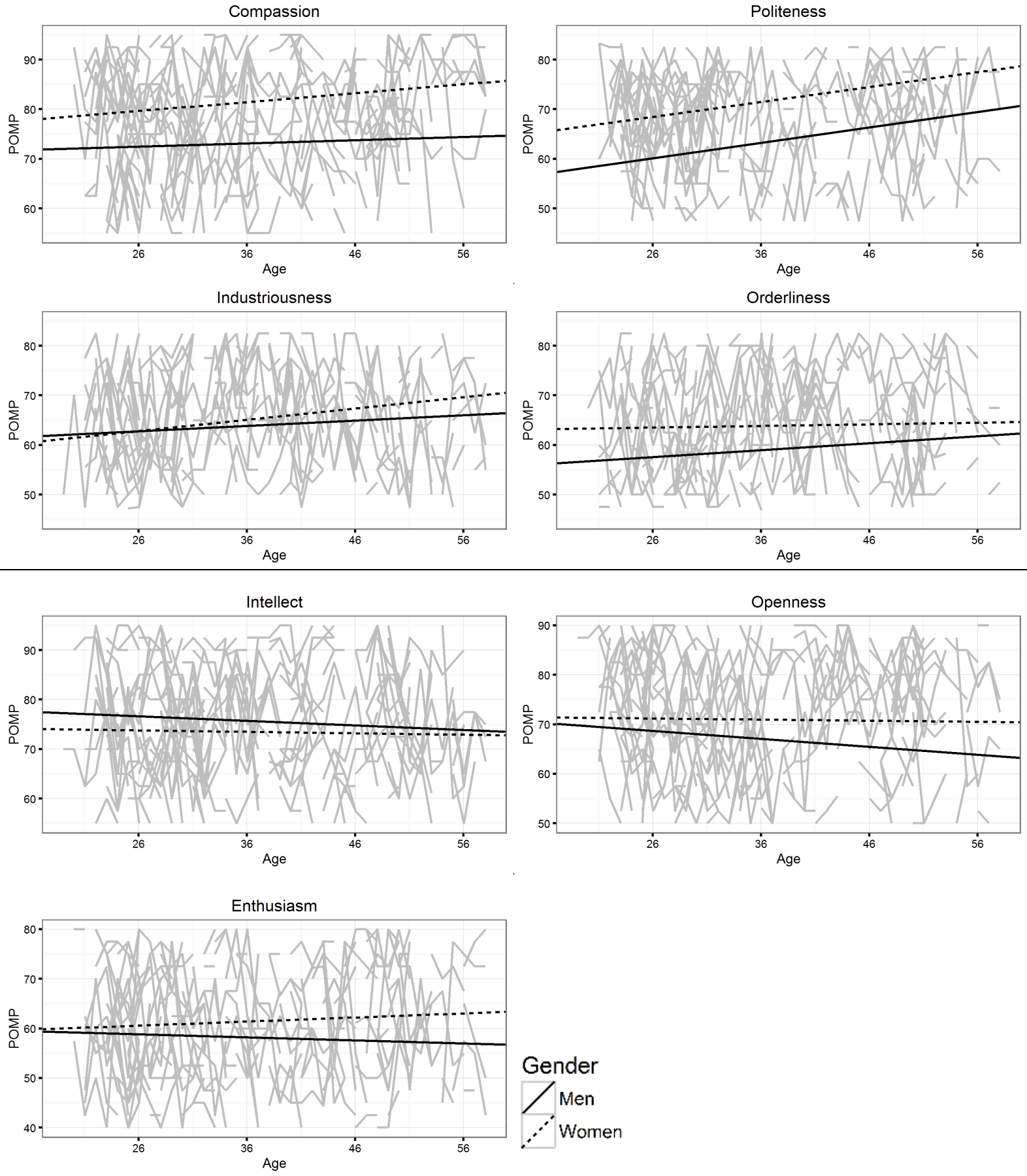

Supplemental Figure S1. Mean-Level Change in Remaining Aspects. Fit lines were constructed based on results from Curve of Factors Models. The grey lines in the background correspond to 300 individual participants' scores across the four time points. 


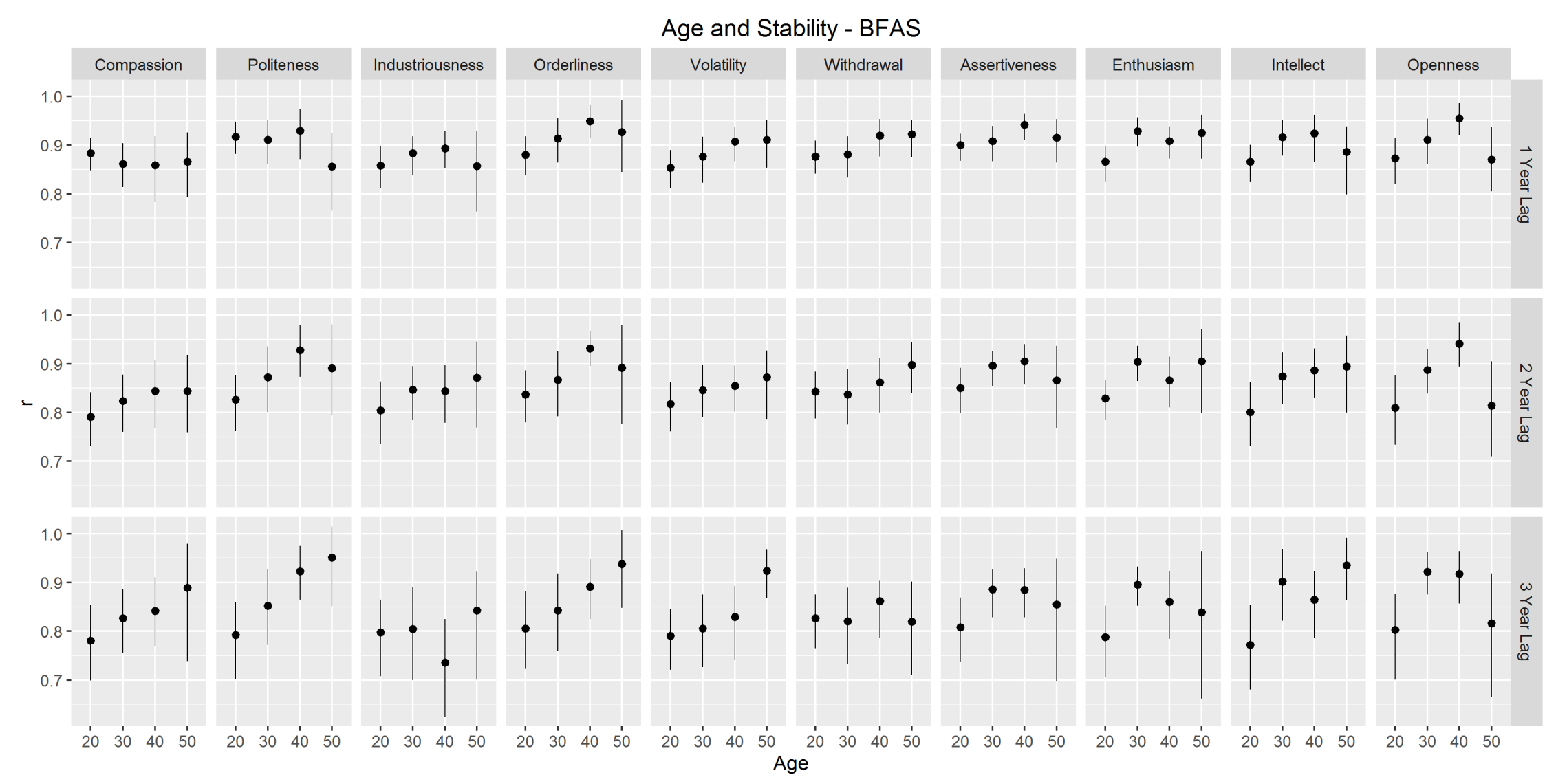

Supplemental Figure S2. Age and Stability for Self-Reported Big Five Aspects. Points represent point estimates for stability correlations, and bars represent $95 \%$ confidence intervals obtained via bootsrapping (500 resamples). 


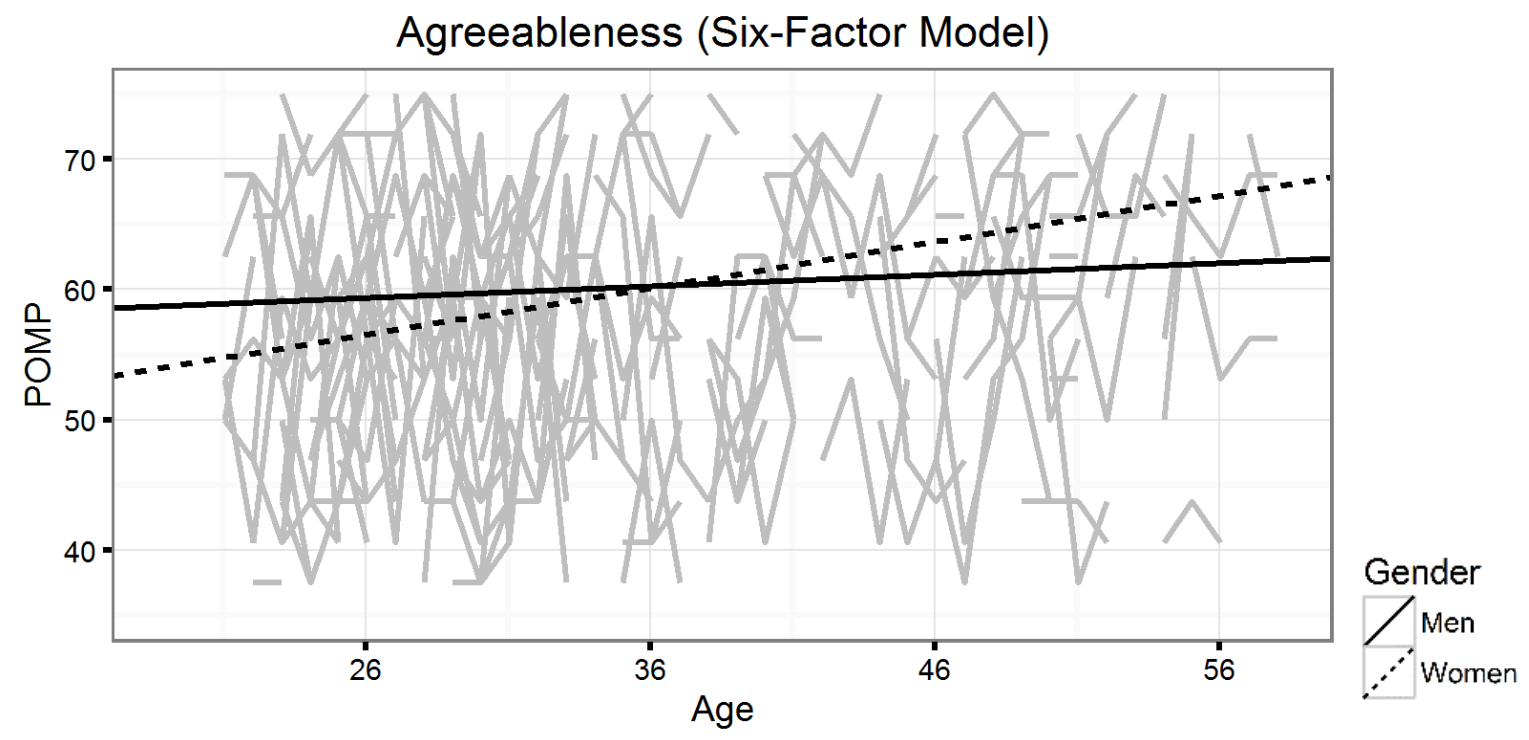

Supplemental Figure S3. Mean-Level Change in Six-Factor Model Agreeableness. Fit lines were constructed based on results from Curve of Factors Models. The grey lines in the background correspond to 300 individual participants' scores across the four time points. 


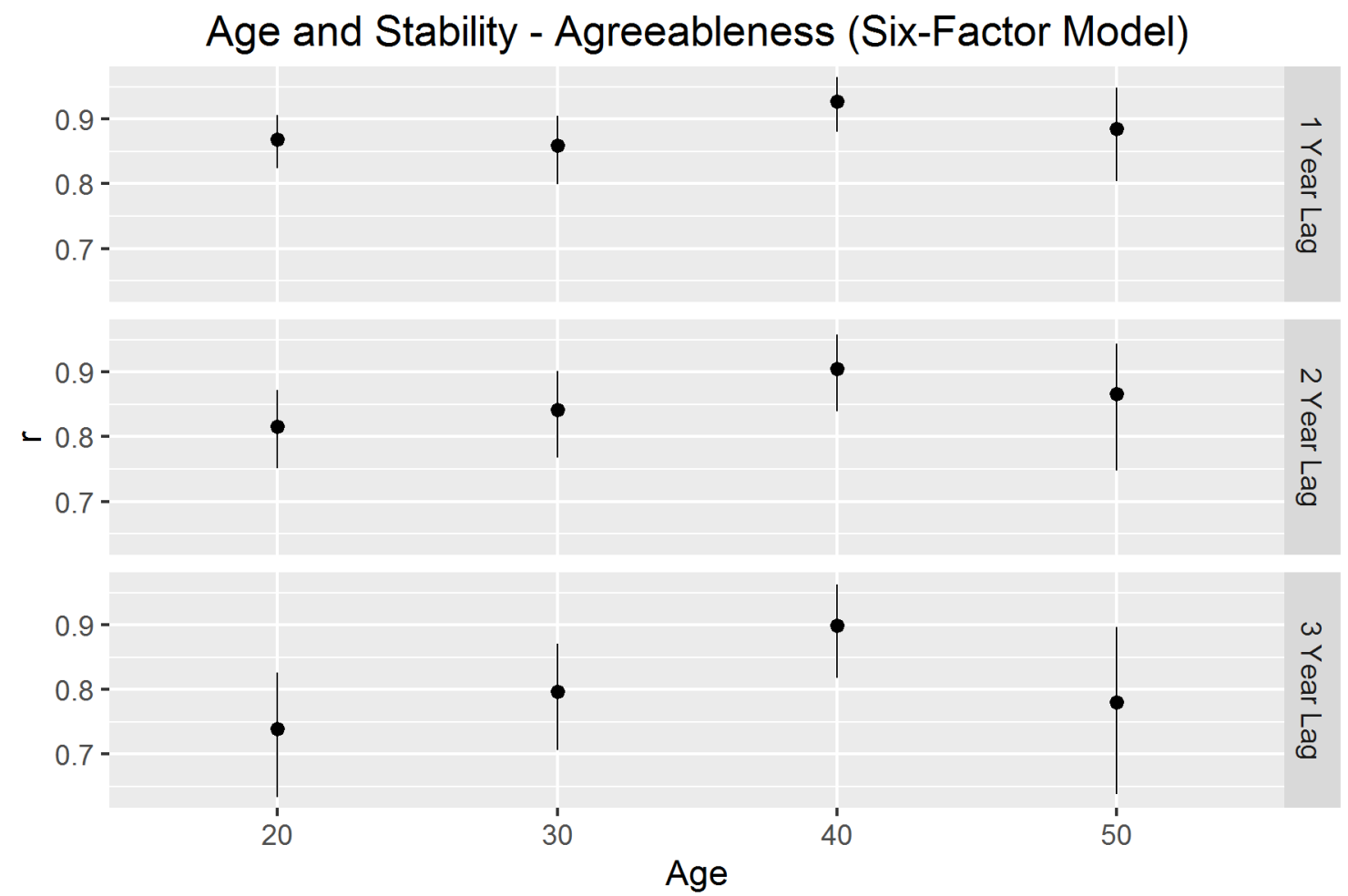

Supplemental Figure S4. Age and Stability for Self-Reported Six-Factor Model Agreeableness. Points represent point estimates for stability correlations, and bars represent $95 \%$ confidence intervals obtained via bootsrapping (500 resamples). 

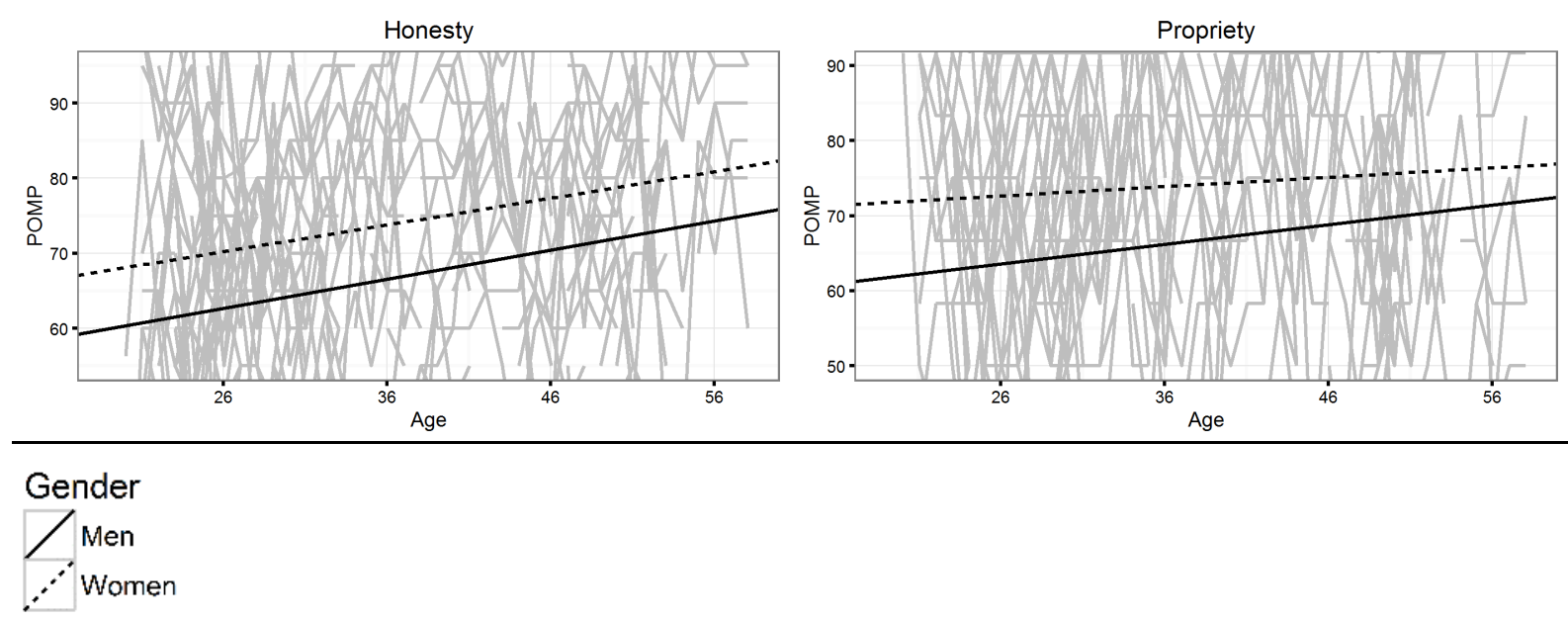

Supplemental Figure S5. Mean-Level Change in Post-Hoc Honesty-Propriety Aspects. Fit lines were constructed based on results from Latent Growth Curve Models. The grey lines in the background correspond to 300 individual participants' scores across the four time points. 


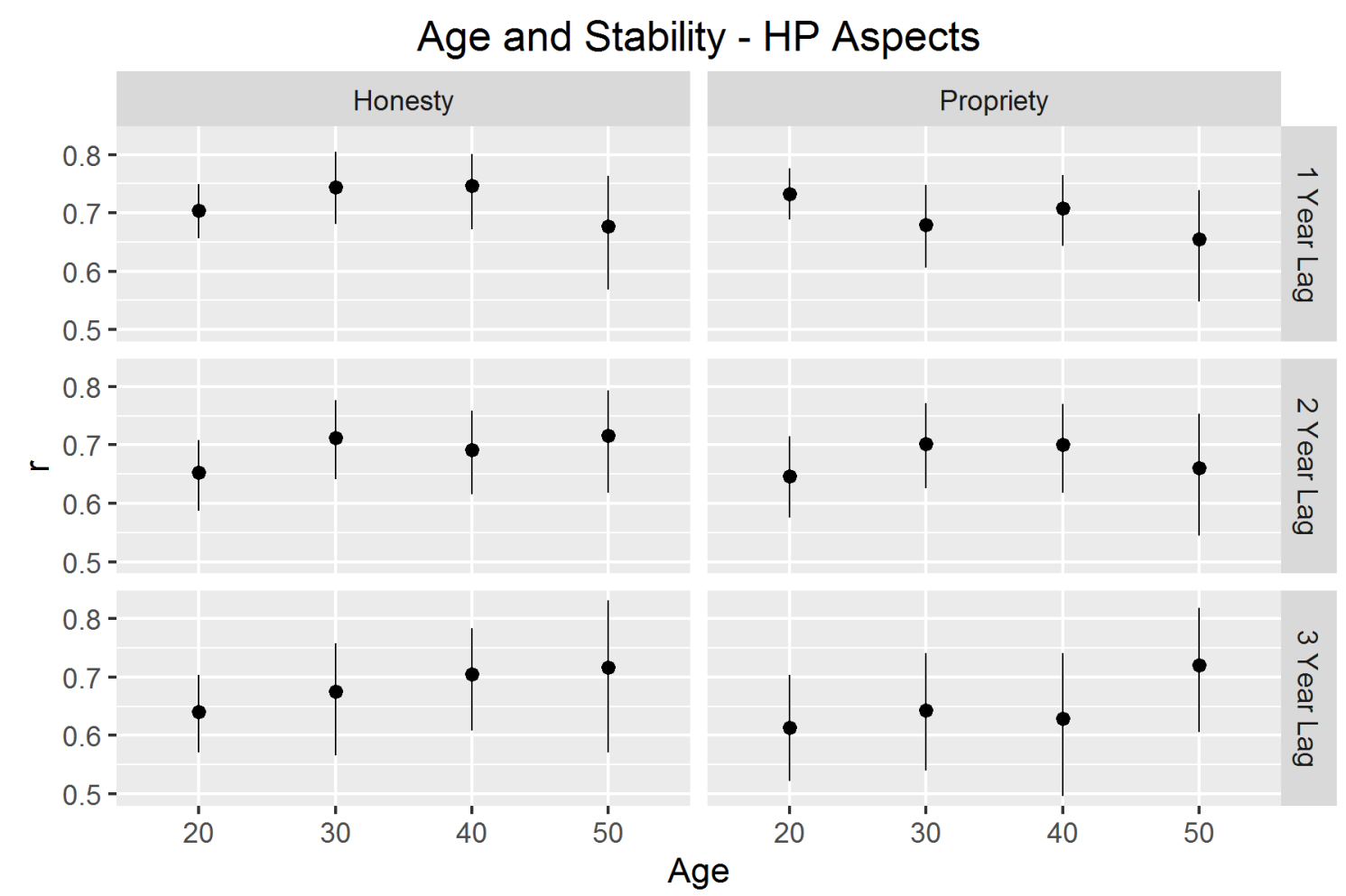

Supplemental Figure S6. Age and Stability for Self-Reported Exploratory Honesty-Propriety Aspects. Points represent point estimates for stability correlations, and bars represent $95 \%$ confidence intervals obtained via bootsrapping (500 resamples). 